\title{
La regulación del acogimiento tras las últimas reformas legislativas en materia de protección a la infancia y a la adolescencia en el derecho español
}

\author{
The new fostering regulation in spanish law \\ for child and teenage protection \\ ROCÍO LÓPEZ SAN LUIS \\ Universidad de Almería, España
}

RECEPCIÓN: 20/08/20I6• ACEPTACIÓN: 3 I/O8/20I 6

\begin{abstract}
RESUMEN El presente trabajo se centra en el estudio de la nueva regulación del acogimiento tras las últimas reformas en materia de protección de menores. Para ello, se analizan los principios rectores de la actuación administrativa, que ha sido objeto de reforma para una correcta adaptación a los acuerdos e instrumentos internacionales firmados por España y a las nuevas necesidades de los menores. Las situaciones de riesgo y de desamparo también son objeto de estudio, dado que con la nueva redacción de los artículos 17 y I 8 de la Ley Orgánica de Protección Jurídica del Menor y el artículo I72 del Código Civil, el legislador pretende garantizar una protección uniforme en todo el territorio nacional siendo referente para las comunidades autónomas. La guarda provisional, las diferentes modalidades de acogimientos — familiar y residencial—, así como la nueva incorporación del estatuto del acogedor familiar ocupan una parte importante del trabajo; terminado con la referencia a las altas funciones que se le encomiendan al Ministerio Fiscal en materia de protección de menores.
\end{abstract}

I. Profesora Titular de Derecho Civil en la Universidad de Almería, España. Correo: rlopez@ual.es. 
PALABRAS CLAVE Protección de menores, situación de riesgo, desamparo, acogimiento.

ABSTRACT This study focuses on the latest legislative reforms with respect to fostering and the protection of minors. We analyze the key principles of the current administration, which have been reformed to coincide with the international agreements signed by Spain as well as the needs of today's children. We also examine high risk situations and cases of neglect. By revising Articles I 7 and I 8 of the LOPFM and Article I72 of the CC, lawmakers have attempted to guarantee uniform national protection and provide an example for autonomous regions. Additionally, the work considers provisional custody, family and residential fostering, and the incorporation of the family fostering statute. We end by reviewing the principle functions of the Public Prosecutor with regard to the protection of minors.

KEYWORDS Protection of minors, high risk situation, neglect, fostering.

\section{Introducción}

Han pasado casi veinte años desde que se aprobó en el sistema jurídico español la Ley Orgánica I/I996, de I 5 de enero, de Protección Jurídica del Menor, de modificación parcial del Código Civil y de la Ley de Enjuiciamiento Civil (en adelante LOPJM). En su momento, la citada Ley no recibió los elogios esperados y sí multitud de críticas, en torno a que si se trataba de una Ley donde solamente se recogían los derechos del menor y ningún tipo de obligaciones con respecto a la sociedad, a sus progenitores o guardadores; que si algunos conceptos habían quedados indeterminados como el de situación de riesgo o declaración de desamparo del menor; que alguno de los diferentes acogimientos familiares no resultaban lo suficientemente operativos, e incluso que el interés del menor se podía ver menoscabado en relación al acogimiento preadoptivo, etcétera² .

2. Roca (2000) p. I 584 . «No por eso debe dejarse de resaltar los cabos sueltos de la nueva regulación, sobre todo a partir de la reforma de I987. Dudas que el legislador estatal tuvo la oportunidad de resolver con ocasión de la LO I/I996, de 25 de enero, de Protección Jurídica del menor (LOPJM). Pero esta fue una oportunidad en buena medida desperdiciada, ya que una buena parte de esa ley puede ser ejemplo de cómo no se debe legislar, ya que resuelve poco, y encima introduce nuevas incertidumbres, 
Además, la ingente legislación autonómica con la que cuenta el Ordenamiento jurídico español en materia de protección de menores ha generado disfunciones y deficiencias a lo largo de los años, que han puesto de manifiesto por los agentes responsables, en la eficacia y las garantías de los sistemas de protección menores; y, si a ello le sumamos la diversificación y disgregación de los servicios de las administraciones públicas que, unidas a una excesiva burocratización de los sistemas, se puede afirmar que todo ello ha repercutido, lógicamente de forma negativa, en la asistencia que se ha prestado en los dieciocho años de vigencia de LOPJM ${ }^{3}$.

Por su parte, los acuerdos e instrumentos internacionales que ha firmado España desde entonces, ha hecho necesaria una revisión de nuestro sistema de protección de la infancia y de la adolescencia, provocando la adaptación de los principios de actuación administrativa a las nuevas necesidades o realidades ${ }^{4}$.

La reforma del sistema de protección de menores se ha llevado a cabo mediante la aprobación de la Ley Orgánica 8/2015, de 22 de julio, de modificación del sistema de Protección a la Infancia y a la Adolescencia ${ }^{5}$ y la Ley 26/20I 5, de 28 de julio, de modificación del Sistema de Protección a la Infancia y la Adolescencia ${ }^{6}$, pretendiendo así el legislador crear un marco legal común que permita homogeneizar la coordinación entre cada uno de los sistemas autonómicos de protección y el resto de los sistemas públicos, dado que en estos años de vigencia de la LOPJM se ha venido reclamando la delimitación de las amplias facultades de las comunidades autónomas en la creación, dirección, organización y gestión de los servicios, instituciones y programas para menores, con el fin de establecer y exigir unos criterios mínimos, a los que someter la gran diversidad de modelos organizativos; así como la homogeneización, a nivel estatal, de los criterios que perfilan cada una de las situaciones de desprotección en que puede encontrase un menor.

generalizaciones, repeticiones innecesarias presentadas como novedades [...] demasiadas palabras hueras, en fin, que en muy poco contribuyen a despejar las incógnitas existentes en transcendente regulación, y que han motivado justificadas críticas por parte de la doctrina».

3. Sainz-Cantero (20I4) p. io9.

4. GonZÁlez (I996) p. 320; NúÑEZ (I996) p. I-7.

5. BOE 23 de julio de 20I 5. Sobre la reforma en la LOPJM tras la LO 8/20I 5 ; IgLeSIA (2OI 5) p. I-6.

6. BOE 28 de julio de 2015 . 
Entre las normas objeto de reforma se encuentran la Ley Orgánica de Protección Jurídica del menor (LOPJM), Código civil, Ley de Adopción internacional, Ley de Enjuiciamiento civil (LEC), Ley de Jurisdicción Contencioso-administrativa, Ley de la Autonomía del Paciente y, por último, la Ley 40/2003, de 18 de noviembre, sobre las condiciones de mantenimiento de los efectos del título oficial de familia numerosa. Siendo objeto de nuestro estudio las reformas introducidas en el ámbito de los acogimientos, nos vamos a centrar en la Ley $26 / 2015$, sin perjuicio de acudir a la Ley Orgánica 8/2015, para mayor abundamiento en el tema central de nuestro trabajo.

Sin entrar en profundidad, y haciendo un estudio a vuela pluma de la reforma pretendida, podemos resaltar las siguientes modificaciones:

En relación a la LOPJM, los artículos 5 y 7 son modificados tras la ratificación por España de la Convención de los Derechos de las Personas con Discapacidad, de $\mathrm{I} 3$ de diciembre de $2006^{7}$. Se introduce el tan demandado capítulo, concretamente un tercero en el Título I, dedicado a los «Deberes de los menores», reconociéndoles no sólo como titulares de derechos sino también sujetos de deberes, atendiendo a diversas normas internacionales y autonómicas. Asimismo, se refuerzan las medidas para el ejercicio de los derechos de los menores, estableciendo un marco regulador para los menores extranjeros que se encuentren en España independientemente de su situación administrativa. Se introducen nuevos principios rectores destacando, fundamentalmente, la actuación administrativa en la protección de los menores contra cualquier forma de violencia, incluida la producida en su entorno familiar, de género, la trata y el tráfico de seres humanos y la mutilación genital femenina, entre otras (art. I I de la LOPJM). En el artículo I 2, que posteriormente se analizará en profundidad dado que es unos de los artículos objeto de este estudio, se recogen los principios rectores que vertebran esta reforma de las instituciones de protección a la infancia y la adolescencia, como la prioridad de las medidas estables frente a las temporales, las familiares frente a las residenciales y las consensuadas frente a las impuestas. A su vez, se establece la obligación de las Entidades Públicas de revisar, en plazos concretos, las medidas de protección adoptadas; establecimiento de plazos que eran muy demandados desde la aprobación de la LOPJM, ya que las medidas se quedaban en papel mojado y el seguimiento personal de los menores al arbitrio de la buena voluntad de los operadores sociales y jurídicos.

7. Instrumento de ratificación de 23 de noviembre de 2007 . 
El legislador también se hace eco de las definiciones o conceptos que se han ido perfilando por parte de la jurisprudencia y las legislaciones autonómicas en torno a las situaciones de riesgo y desamparo, estableciendo una rigurosa y completa regulación. En este sentido, se desarrolla de forma integral las situaciones de riesgo así como su procedimiento y, en cuanto al desamparo, se introducen dos novedades: se completa su definición estableciéndose una norma de carácter estatal y, además, se regula por vez primera la competencia de las Entidades Públicas respecto a la protección de los menores españoles en situación de desprotección en un país extranjero (arts. i 8 LOPJM y I72 del CC).

Como he citado con anterioridad, en la nueva regulación, se modifican diversos artículos en relación a la guarda y al acogimiento de los menores (arts. I9, 2 I LOPJM y I73 del CC). Si bien, como es el objeto central de nuestro trabajo, me referiré en apartados posteriores.

En cuanto a las reformas introducidas en el Código civil, manifestar que guardan una estrecha relación con las operadas en la LOPJM, concretamente en materia de acogimiento y adopción (arts. I72, I73 y I75 CC). Asimismo, determinadas normas de Derecho internacional privado — normas de conflicto- como los apartados 4, 6, y 7 del artículo 9 relativo a la ley aplicable en materia de filiación, a la protección de menores y mayores y a las obligaciones de alimentos. También, se introduce en el artículo is la doble nacionalidad en los supuestos de adopción internacional, cuando el país de origen del menor adoptado prevé la conservación de su nacionalidad. Así como otros preceptos en materia de filiación (art. I33 del CC), principio de agilidad e inmediatez aplicable a los incidentes cautelares que afecten a menores (art. I 58 del CC), sobre el derecho del menor a relacionarse con sus parientes ( 160 y i 6 I del CC) y, finalmente, en relación al consentimiento prestado por los menores, dándose una nueva redacción a los artículos I 263 y I 264 del CC.

No puedo pasar si detenerme, aunque sea de manera breve, en la nueva redacción del párrafo primero del artículo I 263 del Código civil, dado que el consentimiento prestado por los menores, concretamente en el ámbito contractual, fue objeto de un intenso trabajo que publiqué hace años. En él analicé la capacidad del menor atendiendo a sus condiciones de madurez y la responsabilidad derivada de sus actos ${ }^{8}$. Ahora, tras la redacción de este primer párrafo se pone de manifiesto lo que ya sosteníamos muchos autores teniendo en cuenta

8. López (200I) p. 58-65; SÁnchez-Calero (20I I) p. 847-863; Heras (2002) p. $60-67$. 
el segundo párrafo del artículo 2 de la LOPJM, en el que se establecía que las limitaciones a la capacidad del menor se deben interpretar de forma restrictiva9.

No cabe la menor duda de que el legislador teniendo en cuenta la edad del menor y sus condiciones de madurez le ha ido reconociendo un ámbito de actuación donde los actos por él realizados se han considerado válidos. Tanto es así que nos encontramos con diferentes menores: los no emancipados, los emancipados, los de vida independiente, los del supuesto del artículo I64 del CC, y a todos ellos se les va reconociendo un ámbito de actuación donde atendiendo a su capacidad natural de entender y querer los actos por ellos realizados son válidos. Hasta el punto de que si al menor le consideramos que tiene esa capacidad contractual, que la tiene atendiendo a su edad y sus condiciones de madurez debe responder por los actos realizados. Distinto es quién tengan que responder por ellos, el menor con su patrimonio o sus representantes legales, pero lo que está claro es que a mayor capacidad de actuación mayor responsabilidad.

En definitiva, lo que pretende dejar de manifiesto el legislador con la reforma del apartado I del artículo I 263 del CC es que el menor es una persona capaz, y que atendiendo a sus condiciones de madurez puede realizar actos que socialmente están admitidos y que, por tanto, son válidos y que no tienen eficacia claudicante, siendo el menor responsable de ellos ${ }^{10}$.

Ahora bien, centrándome en el objeto de estudio manifestar que solamente me referiré a aquéllas modificaciones que el legislador acomete en materia de acogimiento de menores y también a todas aquellas otras materias que directa o indirectamente están relacionadas con dicha institución de guarda: derechos y obligaciones del menor, situación de riesgo, desamparo, etc.

9. TOldRÁ (2006) p. IOI, «se convendrá con nosotros que de lege ferenda, sería deseable un precepto explícito en el Código civil, de reconocimiento a la plena capacidad para los actos aludidos. Ello supondría un apoyo jurídico objetivo a los jueces que han de dilucidar estos supuestos y que se ven obligados a hacer verdaderos equilibrios deductivos y convincentes para argumentar un imperativo de la realidad social».

io. SAbater (I996) p. 3: consciente de que la redacción del segundo apartado de la LOPJM en el año I996 adoptaba un nuevo sentido y orientación en materia de capacidad del menor bajo argumentos basados en el conocimiento científico, según el cual la mejor forma de garantizar social y jurídicamente la protección a la infancia es promoviendo su autonomía personal, considera excesivo y hasta perjudicial para el menor, predicar como principio la plena eficacia de los actos que realice. 


\section{Principios rectores de la actuación administrativa en la reforma de las instituciones de protección de la infancia y adolescencia}

Para un estudio adecuado de la reforma introducida en materia de acogimientos, es preciso detenernos en la regulación de los principios rectores de la actuación administrativa tras la Ley 26/2005, de 28 de julio, de modificación del Sistema de Protección a la Infancia y a la Adolescencia.

Es en el artículo i de la LOPJM, que mantiene su numeración, donde se regulan los citados principios, si bien ahora dentro del Capítulo IV del Título Primero, al introducirse un nuevo Capítulo III con la rúbrica «Deberes de los menores».

Este artículo ha sido objeto de una gran reforma, al introducirse nuevos principios rectores como consecuencia de los acuerdos e instrumentos internacionales firmados por España, así como la inevitable adaptación de los mismos a las nuevas necesidades que presenta la infancia y la adolescencia ${ }^{11}$.

Como pondré de manifiesto, el legislador ha querido plasmar a largo del articulado su preocupación por los menores con discapacidad, procurando que tanto ellos como sus familias gocen de una especial protección garantizándoles los servicios especializados que precisen, así como el mantenimiento de los mismos cuando los menores son objeto de una medida de protección mediante un acogimiento familiar o residencial. En este sentido, el artículo I I en el párrafo 3 del apartado I señala que:

En todo caso, el contenido esencial de los derechos del menor no podrá quedar afectado por falta de recursos sociales básicos. Se garantizará a los menores con discapacidad y a sus familias los servicios sociales especializados que su discapacidad precise.

Si bien, ha sido en el apartado 2 y los nuevos 3 y 4 del artículo i I donde se han introducido los nuevos principios rectores, además de modificar la redacción de los anteriores, para un mejor entendimiento o aclaración de los mismos.

En efecto, se mantiene como principio rector en las actuaciones de las administraciones públicas el mantenimiento del menor en su familia de origen ${ }^{12}$, salvo que no sea conveniente para su interés, en cuyo caso, y aquí la novedad, se garantizará la adopción de medidas de protección familiares y estables

I I. VAlera (I997) p. 263-265; De La Rocha (2000) p. 23-26.

I2. PÉREZ (I999) p. 28-3 I. 
priorizando, en estos supuestos, el acogimiento familiar frente al institucional. Estos principios son consecuencia, por un lado, del derecho que tiene todo menor a la vida familiar y, por otro, a la actuación subsidiaria por parte de la Administración respecto de los progenitores o tutores a quienes les está encomendada la guarda y, por tanto, la protección del menor, siempre que los padres no cumplan de forma adecuada sus obligaciones legales y los menores no tengan debidamente garantizada su protección y el disfrute de sus derechos ${ }^{13}$. Nótese el Convenio Europeo para la Protección de los Derechos Humanos y de las Libertades fundamentales $(\mathrm{CEDH})^{14}$, que proclama en su artículo 8 el derecho al respeto a la vida familiar:

Toda persona tiene derecho al respeto de su vida privada y familiar... no podrá haber injerencia de la autoridad pública en el ejercicio de este derecho, sino en tanto en cuanto esta injerencia esté prevista por la ley y constituya una medida que, en una sociedad democrática sea necesaria para la protección de la salud, o la moral o la protección de los derechos y las libertades de los demás.

A su vez, la Convención de los Derechos del Niño de Naciones Unidas encomienda a los Estados velar porque el niño no sea separado de sus padres contra la voluntad de éstos, excepto cuando tal separación sea necesaria para el interés superior del menor (art. 9.I). Asimismo, nuestra CE contempla el derecho a la vida familiar, no sólo en el artículo 39, sino también quedaría comprendido en el derecho fundamental a la intimidad familiar que reconoce el artículo i 8.I.

En este sentido, el legislador en la reforma del artículo I 2 de la LOPJM establece que en las actuaciones de protección deberán primar, en todo caso, las medidas familiares frente a las residenciales, las estables frente a las temporales y las consensuadas frente a las impuestas. Y es que como se verá, las entidades públicas a las que les está encomendada la protección de los menores en cada Comunidad Autónoma, a la hora de declarar una situación de riesgo o desamparo y establecer alguna medida de protección sobre el menor y, en su caso, acordar algunas de las modalidades de acogimiento, tienen que tener muy presente que la Administración debe llegar donde los progenitores o tutores no

i3. De Palma (20i i) p. i 87.

I4. Roma, 4 de noviembre de I950. 
pueden o no quieren y velar por los derechos de menor, siendo la actuación de la Administración subsidiaria respecto de aquéllos. Tanto es así que, las medidas acordadas por la Administración van a ser siempre temporales para que los menores puedan lo antes posible, y siempre que no sea perjudicial para el menor, volver con su familia. Para ello, se elaborarán proyectos de intervención socio-familiar o, en su caso, programas de reintegración familiar, para evitar la ruptura del vínculo familiar y donde los padres, tutores se comprometan a trabajar con la intervención de profesionales logrando el retorno del menor con su familia. Por ello, es de suma importancia que las medidas acordadas entre la Entidad Pública y los progenitores o tutores sean consensuadas.

Un claro ejemplo de lo manifestado con anterioridad es la nueva redacción del artículo I9 de la LOPJM en relación con el artículo I 72 bis del CC, estableciendo una guarda voluntaria del menor de duración máxima de dos años, salvo que el interés superior del menor aconseje, excepcionalmente, la prórroga de la misma, cuando los progenitores o tutores no pueden cuidar de un menor por circunstancias graves y transitorias. Guarda acordada con los progenitores o tutores que llevará aparejado el compromiso de la familia de someterse, en su caso, a la intervención profesional para intentar, por todos los medios, el regreso del menor con su familia de origen, en virtud del derecho a la vida familiar que tiene reconocido.

Otro de los principios rectores de la actuación de los poderes públicos es la prevención y detección precoz, de las situaciones que puedan perjudicar el desarrollo personal del menor. Esto es, el legislador en su empeño de que los menores no salgan de su familia, insta a las administraciones públicas y también a la ciudadanía a la sensibilización ante cualquier situación de riesgo o desprotección ante la que se pueda encontrar todo menor, para que se puedan promover medidas orientadas a la disminución del riesgo y preservar al menor en su entorno familiar. Un claro ejemplo de ello es la nueva redacción de las actuaciones en situaciones de riesgo, entre las que se encuentra la protección al concebido o prenatal. ( $c f r$. art. I I.2 d) y I 7 de la LOPJM).

Se siguen manteniendo los principios de sensibilización de la población, promoción de la participación, voluntariado y solidaridad social, así como la objetividad, imparcialidad y seguridad en la actuación protectora, el carácter colegiado e interdisciplinar en la adopción de las medidas que les afecten y el principio de supremacía del interés del menor ${ }^{15}$, que tras la aprobación de

I 5. Moreno-Torres (2007) p. 9-I4; Linancero (200I) p. 54-86. 
la Ley 8/20I5, de 22 de julio, de modificación del Sistema de Protección a la Infancia y a la Adolescencia ha sido reforzado como principio prioritario en la adopción de toda medida de protección, dotándolo de contenido mediante la incorporación de la jurisprudencia del Tribunal Supremo de los últimos años en atención los criterios de la Observación General núm. I4, de 29 de mayo de 2013, del Comité de Naciones Unidas del Derechos del Niño ${ }^{16}$.

Se incluye un importantísimo principio en la letra i) del párrafo 2 del artículo I I, como observancia de las normas firmadas por España en atención a «la protección contra toda forma de violencia, incluido el maltrato físico, psicológico, los castigos físicos humillantes y denigrantes, el descuido o trato negligente, la explotación, los abusos sexuales, la corrupción, la violencia de género o en el ámbito familiar, educativo, sanitario o social o educativo, incluyendo el acoso escolar, así como la trata y el tráfico de seres humanos, la mutilación genital femenina y cualquier otra forma de abuso» ${ }^{17}$.

Asimismo, se introducen cuatro apartados que se corresponden con las letras la j), k), 1) y m) donde se plasman los nuevos principios como: la igualdad de oportunidades y no discriminación, la accesibilidad universal de los meno-

I6. En este sentido, la Exposición de Motivos señala que el interés del menor «se define desde un contenido triple. Por una parte, es un derecho sustantivo en el sentido de que el menor tiene derecho a que cuando se adopte una medida que le concierna, sus mejores intereses hayan sido evaluados y, en el caso de que haya otros intereses en presencia, se haya ponderado a la hora de llegar a una solución. Por otra parte, es un principio general de carácter interpretativo, de manera que si una disposición jurídica puede ser interpretada en más de una forma se debe optar por la interpretación que mejor responda a los intereses del menor. Pero además, en último lugar, este principio es una norma de procedimiento. En estas tres dimensiones el interés superior del menor tiene una misma finalidad: asegurar el respeto completo y efectivo de todos los derechos del menor así como su desarrollo integral. RavetLlat (2015) p. Io; Gómez (2000) p. 25; Guilarte (20I4) p. I39; Baeza (200I) p. 355-362; Cillero (i990) p. 62; Rivero (2000) p. I 543-I 549; CAMPO (20I 5 ) p. 2-3.

I7. Convenio del Consejo de Europa relativo a la protección de los niños contra la explotación y el abuso sexual, hecho en Lanzarote el 25 de octubre de 2007, ratificado el 5 de agosto de 20io. Observación hecha por el Comité de los Derechos del Niño de Naciones Unidas núm. I3 de 20I I, sobre el derecho del niño a no ser objeto de ninguna forma de violencia. Por parte del Defensor del Pueblo en el documento sobre «La trata de seres humanos en España: Víctimas invisibles», 20I2. (Cfr. Preámbulo del Proyecto de ley). 
res con discapacidad, así como su inclusión y participación plenas y efectivas, el libre desarrollo de la personalidad conforme a su orientación e identidad sexual y el respeto y valoración a la diversidad étnica y cultural.

Por último, se incluyen dos nuevos párrafos en el artículo i I, siendo los dos de suma importancia. El primero de ellos, el apartado 3, va dirigido a la sensibilización, prevención, detección, notificación, asistencia y protección de cualquier forma de violencia contra la infancia y la adolescencia. Con este párrafo, el legislador quiere transmitir la importancia de que toda la sociedad se responsabilice ante cualquier tipo de violencia y en especial con los más vulnerables, los menores. Para ello, insta a los poderes públicos que mediante los procedimientos oportunos aseguren la coordinación entre las distintas administraciones, entidades colaboradoras y servicios, tanto públicos como privados, para garantizar una actuación integral.

Y, para terminar, en el apartado 4 se recoge como principio rector en la actuación administrativa, una de las grandes preocupaciones para los diversos profesionales que tratan con los menores que se encuentran bajo algunas de las medidas de protección establecidas en la LOPJM y del CC, como es la salida de estos menores una vez que han alcanzado la mayoría de edad. En este sentido, el legislador insta a las Entidades Públicas a que «...dispongan de programas y recursos destinados al apoyo y orientación de quienes, estando en acogimiento, alcancen la mayoría de edad y queden fuera del sistema de protección, con especial atención a los que presentan discapacidad». Principio que se materializa con la inclusión del artículo 22 bis en la citada Ley, en el que se establecen programas de preparación para la vida independiente de los menores.

Nótese que, aunque éstos son los principios rectores que deben primar en la actuación de los poderes públicos en relación con los menores que la LOPJM recoge en el artículoi i, debemos mencionar otros principios citados bien de manera explícita bien de manera implícita, a lo largo de la Ley objeto de estudio que deben inspirar toda actuación por parte de la Administración a la hora de tomar alguna medida de protección sobre cualquier menor.

Así, destacamos el carácter progresivo y flexible de las medidas acordadas o declaradas por parte de la Entidad Pública. Esto es, las entidades públicas a la hora de establecer las medidas de protección deben tener muy en cuenta la situación de los menores y de su entorno familiar elaborando proyectos socioeducativos o planes individuales de protección para cada menor, tal y como se pone de manifiesto en el artículo 2i de la LOPJM. Es más, las medidas deben 
de ser progresivas, es decir, salvo que el interés del menor aconseje tomar una medida permanente, las entidades públicas irán acordando medidas progresivas para ir trabajando con el menor y su entorno familiar, y sólo cuando no sea posible se separará al menor de sus progenitores o tutores de manera provisional, mediante una declaración de desamparo, y todo ello con la finalidad de volver a reintegrar al menor con su familia de origen, y sólo cuando no sea posible acordar la adopción o el acogimiento familiar permanente, porque las circunstancias no lo aconsejan, se recurrirá al acogimiento residencial ya que, como hemos dicho con anterioridad, el principio de reintegración familiar supone que cuando fuera conveniente adoptar medidas de protección que impliquen la separación del menor de su familia, tendrá carácter preferente el acogimiento familiar respecto el residencial, y la acogida en familia extensa respecto de la acogida en familia ajena; configurándose en nuestro Ordenamiento Jurídico como el ámbito idóneo para la asistencia, formación y socialización del menor.

Un claro ejemplo del carácter temporal, flexible y progresivo de las medidas de protección es el apartado 5 del artículo I 2 de la LOPJM cuando establece que:

Cualquier medida de protección no permanente que se adopte respecto de menores de tres años se revisará cada tres meses, y respecto de los mayores de esa edad se revisará cada seis meses. En los acogimientos permanentes la revisión tendrá lugar el primer año cada seis meses y, a partir del segundo año, cada doce meses.

Con la inclusión de plazos — tres, seis, doce meses- el legislador pretende evitar que las medidas acordadas por la Entidad Pública, que en un principio eran necesarias, puedan devenir lesivas tanto para el menor como para su familia ${ }^{18}$. En este sentido, podemos recordar casos sobre la declaración de desamparo y acogimiento de dos menores sevillanos (STC I24/2002, de 20 de mayo) y el de una menor de Castilla la Mancha y el retorno a la familia biológica (STS de 3 I de Julio de 2009) donde, finalmente, la Administración ha tenido que indemnizar a los padres biológicos cuando la vuelta del menor

i 8. De Palma (20I I) p. i 89: «la actuación de las administraciones públicas deberán tener un carácter flexible, lo que supone que el conjunto de medidas de protección adoptadas deberán ser revisadas periódicamente para adaptarlas en todo momento a la cambiante situación del menor y su familia. Así, situaciones inicialmente declaradas de riesgo pueden pasar a ser calificadas de desamparo y viceversa». 
con su familia de origen era contrario al interés del menor, porque desde que se declaró el desamparo hasta que los jueces determinaron la anulación del mismo habían transcurridos muchos años sin que los menores hubiesen tenido contacto alguno con sus familiares, y el regreso con su familia biológica se hacía inviable ${ }^{19}$.

\section{Modificaciones en las instituciones de protección de menores para un marco legal común estatal: situación de riesgo y desamparo}

En la legislación estatal y autonómica se distinguen tres situaciones de desprotección en la que se puede encontrar un menor: riesgo, desamparo y dificultad social, y donde la actuación de la administración competente se gradúa atendiendo a la gravedad del caso. Como señalaré a continuación, la calificación de la situación menor- riesgo o desamparo- determinará si se le separa o no de su familia, y en caso de ser separado, si se sujeta a «guarda administrativa» o a «tutela»; ésta última, implica la suspensión de la patria potestad o la tutela a que estuviera sometido el menor.

\section{A. Delimitación legal de los supuestos de situación de riesgo y sus consecuencias. Nueva redacción del artículo 17 de la LOPJM}

El legislador de 1996 haciéndose eco de la necesaria delimitación e interpretación restrictiva del concepto de desamparo que establecía la Ley de I987, que modificó sustancialmente el Código civil en materia de protección de menores, estableció la diferenciación entre situación de riesgo y desamparo. Si bien, la definición de situación de riesgo no estaba lo suficientemente determinada y la concreción de la misma se hacía sobre la de desamparo. Ello generó que las legislaciones autonómicas y la jurisprudencia fuesen configurando los supuestos para determinar cuando estábamos ante una situación u otra, estableciendo, como hemos dicho con anterioridad, una extensa diversificación casuística con diferentes formas de actuación por parte de la Administración, que provocaba que los menores fuesen tratados de manera distinta en cada comunidad autónoma y la actuación por parte de la Administración muy diversa, poniendo de manifiesto una falta de coordinación entre las administraciones.

En efecto, el legislador de 1996 incorporó la situación de riesgo a nuestro

i9. Benavente (201 i) p. 33-43. 
Ordenamiento jurídico ante la necesidad de interpretar de forma restrictiva el desamparo, ya que esta última situación de desprotección comporta la asunción de la tutela del menor por la Administración y la adopción de medidas que implican la separación del menor de su familia, incidiendo, por tanto, de forma directa y grave en el derecho a la vida familiar. Así, el legislador buscó garantizar que la regulación de la protección de menores tuviera cierta uniformidad, acogiendo la distinción establecida por las legislaciones autonómicas entre situaciones de riesgo y desamparo.

No obstante, y a pesar de la distinción, el legislador no definió ni detalló las situaciones de riesgo, simplemente recogió en el artículo I 2 las situaciones de riesgo como una de las formas de intervención pública para brindar protección a los menores «la prevención y reparación de situaciones de riesgo"; y, en el artículo I7 dispuso que «En situaciones de riesgo de cualquier índole que perjudiquen el desarrollo personal o social del menor, que no requieran la asunción de la tutela por ministerio de la ley, la actuación de los poderes públicos deberá garantizar en todo caso los derechos que le asisten y se orientará a disminuir los factores de riesgo y dificultad social que incidan en la situación personal y social en que se encuentran y a promover los factores de protección del menor y de su familia. Una vez apreciada la situación de riesgo, la Entidad Pública competente en materia de protección de menores, pondrá en marcha las actuaciones pertinentes para reducirla y realizará el seguimiento de la evolución del menor en la familia».

Ahora bien, el artículo I7 no establecía las condiciones para la declaración de riesgo y tampoco el procedimiento o las actuaciones a adoptar por parte de la Administración. Si bien, como se desprende del precepto, la declaración de riesgo acarreaba la actuación paliativa de la Administración, que debía poner los medios para solucionarlo, pero sin asumir la tutela del menor ni suspender la patria potestad ejercida por sus padres. En definitiva, comportaba la adopción de medidas de protección en el entorno socio-familiar entre las que se encontraba: la asistencia acompañada al menor a centros educativos, la ayuda a domicilio dirigida a favorecer la atención del menor y hacer posible su permanencia en la familia, la atención en centros de día fuera del horario escolar, la intervención pisco-terapéutica y programas educativos; en definitiva, cualquier medida que permitiese minimizar los factores de riesgo en el propio entorno socio-familiar del menor ${ }^{20}$.

20. Gisbert (I996) p. I2-I8. 
Con la nueva redacción del artículo i7 de la LOPJM el legislador ha querido salvar todo lo acontecido con anterioridad y dar un completo desarrollo de la situación de riesgo, determinando la competencia para apreciarla y estableciendo el procedimiento para declararla, disponiendo, por seguridad jurídica, que dicha declaración se formalizará en resolución administrativa en casos de especial gravedad, con la información a los padres de cómo deben actuar para evitar una futura declaración de desamparo ${ }^{21}$.

Así se considera situación de riesgo:

Aquella en la que, a causa de circunstancias, carencias, o conflictos familiares o sociales o educativas, el menor se vea perjudicado en su desarrollo personal, familiar y social o educativo, en su bienestar o en sus derechos de forma que, sin alcanzar la entidad, intensidad o persistencia que fundamentaría su declaración de situación de desamparo y la asunción de la tutela por ministerio de la ley, sea precisa la intervención de la Administración pública competente, para eliminar, reducir o compensar las dificultades o inadaptación que le afectan y evitar su desamparo y exclusión social, sin tener que ser separado de su entorno familiar...

Ante cualquier situación de esta índole, la Administración pública tendrá que garantizar los derechos del menor y orientar su actuación en la disminución de los indicadores de riesgo, promoviendo medidas para la protección y preservación de la situación personal del menor y de su entorno familiar. Para ello, la Administración tendrá que estar en coordinación con los centros escolares, servicios sociales y sanitarios y, en su caso, con las entidades colaboradoras del respectivo ámbito territorial para eliminar, reducir o compensar las dificultades que puedan afectar al menor y evitar en un futuro la declaración de desamparo. La Ley considera indicador de riesgo, entre otros, tener un hermano declarado en situación de riesgo, salvo que las circunstancias familiares haya cambiado de forma evidente. Así como la concurrencia de circunstancias o carencias materiales, que nunca podrán desembocar en la separación del menor de su entorno familiar. (cfr. I7.I in fine LOPJM).

El legislador, siendo fiel al derecho del menor a la vida familiar y al principio de subsidiariedad progresiva de la intervención de la Administración, introduce como novedad la elaboración de «un proyecto de intervención socio

2i. Alleuva (20I I) p.i7. 
y educativo familiar» ${ }^{22}$, para la valoración de la situación de riesgo, donde se recogerán las actuaciones, recursos, previsión de plazos, promoviendo los factores de protección del menor y el mantenimiento del menor en su entorno familiar. Así, el legislador considera de suma importancia, en primer lugar, el trabajo individualizado con los menores y sus progenitores, tutores o acogedores acorde con sus propias circunstancias - flexibilidad en las medidas-, y, en segundo lugar, teniendo en cuenta el principio de que prevalecerán las medidas consensuadas frente a las impuestas, la colaboración activa por parte de los progenitores, tutores o guardadores en la elaboración del proyecto de intervención social y educativo familiar. En cualquier caso, será oída y tenida en cuenta la opinión de éstos a la hora de elaborar el proyecto así como la de los menores si tuviesen suficiente madurez y, en su caso, a partir de los I 2 años.

Para el cumplimiento del citado proyecto el legislador prevé que sea firmado por las partes, a las que se le comunicará en formato accesible. En este punto, el legislador no determina con claridad quienes son las partes que tienen que firmar el proyecto de intervención social y educativo familiar Si bien, siguiendo el iter legislativo de la reforma de la LOPJM, el Proyecto de Ley de 27 de febrero de 2015 , distinguía entre elaboración de proyecto y firma de convenio, estableciendo que el proyecto se recogería en un convenio suscrito entre la Administración pública competente y los progenitores, tutores, guardadores y acogedores, determinando que la negativa a la suscripción del convenio como la omisión de la colaboración prevista daría lugar a la declaración de la situación de riesgo.

En consonancia con este planteamiento, debemos entender que aunque no se especifique en la Ley 26/20I 5 el proyecto de intervención social y educativo familiar debe ser firmado por los progenitores, guardadores o acogedores. $\mathrm{Si}$ bien, en la última redacción de la Ley se ha eliminado que la negativa a la firma del proyecto conlleve la declaración de la situación de riesgo, pero sí la no colaboración prevista en el mismo.

22. Algunas Comunidades Autónomas ya recogían la elaboración de un proyecto de elaboración individual. En este sentido, Andalucía en el Decreto 283/2002, de I 2 de noviembre, dentro del artículo ıo. I relativo al derecho a la información de los menores en acogimiento, señala que «los menores tendrán derecho a que se les informe, atendiendo para ello a su grado de madurez, sobre las siguientes cuestiones: b) Plan de intervención individualizada...» Y el artículo I2 se refiere al derecho al "Trato individualizado». 
Ha sido muy acertada la eliminación en el texto definitivo la diferenciación entre el proyecto y el convenio ${ }^{23}$. No obstante, creo que hubiese sido importante mantener que la omisión a suscribir dicho proyecto así como la no colaboración en la ejecución de las medidas acordadas conlleva la declaración de situación de riesgo, puesto que la implicación de los progenitores, guardadores o acogedores es necesaria para disminuir todos los factores de riesgos en los que se pueda encontrar un menor y así obligarles a que se responsabilicen de sus hijos o de los menores que tienen bajo su guarda. La Administración debe respetar el principio de no injerencia en la vida de familiar, pero eso no quiere decir que no pueda obligar a los progenitores, guardadores o acogedores a que asuman sus responsabilidades para con sus hijos o menores que se encuentren bajo su guarda, obteniendo para ello su compromiso, y en caso de que no cumplimiento del citado proyecto es cuando la Administración tendrá que declarar la situación de riesgo o la declaración de desamparo y, con ello, la asunción de la tutela del menor. Por todo ello, considero que el legislador debería haber mantenido la redacción dada en un inicio al apartado 5 del artículo 17 del Proyecto en el sentido de que las partes tendrían que suscribir el Proyecto de intervención social y educativo familiar, y que su negativa a la firma del mismo o su no colaboración en las medidas acordadas o impuestas conllevaría la declaración de situación de riesgo.

En cuanto al procedimiento, en la nueva redacción del artículo I7 se establece que la declaración de riesgo será declarada por la Administración pública mediante resolución administrativa motivada, previa audiencia a los progenitores, tutores, guardadores o acogedores y del menor si tuviese madurez y, en todo caso, a partir de los doce años. La resolución incluirá las medidas tendentes a corregir la situación de riesgo del menor. Frente a esta resolución administrativa se podrá interponer recurso conforme a la Ley de Enjuiciamiento civil2 ${ }^{24}$. En todo caso, si la Administración pública competente aprecia que existe una situación de desprotección que puede requerir la separación del menor de su ámbito familiar o cuando concluido el periodo propuesto en el proyecto de intervención no se hayan conseguido los cambios en el desempeño de los deberes de guarda, que garanticen la necesaria asistencia moral o mate-

23. En la redacción dada por el Proyecto de Ley de 27 de febrero de 20I 5 , podíamos apreciar que el proyecto de intervención social y educativo y el convenio suscrito por las partes, eran cosas distintas.

24. Cfr. 780 Ley de Enjuiciamiento Civil. 
rial del menor lo pondrá en conocimiento de la Entidad Pública, a fin de que valore la procedencia de declarar la situación de desamparo, comunicándolo al Ministerio Fiscal.

Como novedad y prueba del interés que tiene el legislador del seguimiento de las medidas acordadas y la coordinación entre las administraciones autonómicas cuando un menor y su familia están sometidos a intervención por situación de riesgo, establece en el apartado 7 de artículo I 7 de la LOPJM lo siguiente.

Cuando la Administración pública competente esté desarrollando una intervención ante una situación de riesgo de un menor y tenga noticia de que va a ser trasladado al ámbito de otra entidad territorial la Administración pública de origen lo pondrá en conocimiento de la de destino al efecto de que, si procede, ésta continúe la intervención que venía realizando, con remisión de la información y documentación necesaria. Si la Administración pública de origen desconociera el lugar de destino podrá solicitar el auxilio de las Fuerzas y Cuerpos de Seguridad a fin de que procedan a su averiguación. Una vez conocida la localización del menor se pondrá en conocimiento de la Entidad Pública competente en dicho territorio, que continuará la intervención.

Importante es la previsión recogida en el apartado io del artículo i 7 de la citada Ley en relación al caso especialmente grave de atención sanitaria necesaria para el menor y no consentida por sus padres, para el que se disponen actuaciones específicas que implican la correspondiente modificación de la Ley de Autonomía del paciente:

La negativa de los progenitores, tutores, guardadores o acogedores a prestar el consentimiento respecto de los tratamientos médicos necesario para salvaguardar la vida o integridad física o psíquica de un menor constituye una situación de riesgo. En tales casos, las autoridades sanitarias, pondrán inmediatamente en conocimiento de la autoridad judicial, directamente o a través del Ministerio Fiscal, tales situaciones a los efectos de que se adopte la decisión correspondiente en salvaguarda del mejor interés del menor ${ }^{25}$.

25. Sobre este tema es de sumo interés la Circular I/201 2 de la Fiscalía General del 
Por último, me referiré a la protección que la Ley 26/201 5 otorga al prenatal en el apartado 8 del artículo I7, al considerar que determinadas actividades de la madre pueden generar una situación de riesgo y, por tanto, toma medidas sobre ella, para evitar en un futuro la declaración de riesgo o desamparo del recién nacido. Así, el citado precepto señala que:

La Administración pública competente para intervenir en la situación de riesgo adoptará, en colaboración con los servicios de salud correspondiente, las medidas adecuadas de prevención, intervención y seguimiento, de las situaciones de posible riesgo prenatal, a los efectos de evitar con posterioridad una eventual declaración de situación de riesgo o desamparo del recién nacido. A tales efectos, se entenderá por situación de riesgo prenatal la falta de cuidado físico de la mujer gestante o el consumo abusivo de sustancias con potencial adictivo, así como cualquier otra acción propia de la mujer o de terceros tolerada por ésta, que perjudique el normal desarrollo o pueda provocar enfermedades o anomalías físicas mentales o sensoriales al recién nacido. Los servicios sociales de salud y el personal sanitario deberán notificar esta situación a la administración pública competente, así como al Ministerio Fiscal. Tras el nacimiento se mantendrá la intervención con el menor y su unidad familiar para que, si fuera necesario, se declare la situación de riesgo o desamparo del menor para su adecuada protección.

La preocupación sobre la protección al nasciturus es un problema que se viene poniendo de manifiesto por parte de diferentes profesionales (psiquiatras, psicólogos, trabajadores sociales), dado que diferentes estudios ponen de manifiesto como el consumo de drogas - heroína y cocaína- y el tratamiento de metadona para los toxicómanos produce lesiones visuales, auditivas, malformaciones, etc... en el feto; lo que ha originado diferentes debates en torno a la protección del nasciturus y las medidas a adoptar ${ }^{26}$.

Quisiera resaltar que, sin perjuicio de reconocer el daño que el consumo de alcohol, drogas o sustancias con potencial adictivo por parte de una mujer embarazada puede ocasionar en el concebido y que el legislador debe actuar

Estado «Sobre el tratamiento sustantivo y procesal de los conflictos ante transfusiones de sangre y otras intervenciones médicas sobre menores de edad en caso de riesgo grave».

26. MarTínez (2007), p. 96-Io0. 
al respecto para proteger el desarrollo normal del feto, no llego a comprender como el legislador considera que el consumo de sustancias con potencial adictivo pone en riesgo la salud del concebido o prenatal y, sin embargo, por otro lado se aprueba la Ley del aborto ${ }^{27}$. Es decir, al legislador, le preocupa mucho más que el recién nacido nazca con deficiencias físicas o mentales, consecuencia de una vida desordenada de la madre, que la interrupción del embarazo, lo que implica, y por decirlo de una forma política y jurídicamente correcta, privar al prenatal o concebido, de su derecho a la vida. Ello me lleva a preguntarme ¿qué es lo que realmente le preocupa al legislador?, ¿los costes que supone un recién nacido enfermo o con anomalías físicas o psíquicas o la futura vida de un ser humano?. Dicho de otra manera, al legislador le preocupa, y con razón, que el concebido nazca sano, protegiéndolo durante su gestación incluso estableciendo medidas adecuadas para su prevención y seguimiento, pero si la madre decide abortar o interrumpir el embarazo, el prenatal no tiene ningún derecho, ni siquiera al derecho más importante y fundamental que tenemos todo ser humano como es el derecho a la vida. Es por ello que, no puedo dejar de resaltar las contradicciones a las que nos tiene acostumbrados el legislador español y máxime cuando el Preámbulo de la Declaración Universal de los Derechos del Niño establece que «el niño por su falta de madurez física y mental, necesita protección y cuidados especiales, incluso la debida protección legal, tanto antes como después del nacimiento, encontrándose dentro de esta protección el derecho a la vida».

\section{B. La situación de desamparo}

El desamparo, que tuvo una regulación específica con la modificación de los artículos I72, I73, I73 bis y I74 del CC en la LO I/I996, de I 5 de enero, de Protección Jurídica del Menor $^{28}$, de nuevo es objeto de una profunda reforma,

27. Ley Orgánica I I/20 I 5, de 2 I de septiembre, para reforzar la protección de las menores y mujeres con capacidad modificada judicialmente en la interrupción voluntaria del embarazo. BOE, 22 de septiembre de 2015 .

28. Las situaciones de desprotección social de los menores se regulaba en los artículos I 2 a 22 del la LOPJM diferenciando por primera vez las situaciones denominadas «de riesgo" de las denominadas de "desamparo» y sustituyendo el termino de «abandono» por éste último, tal y como venía recogido en la Ley 2/I987, de i I de noviembre. 
pues desde la aprobación de aquélla, hace ya casi veinte años, en torno al artículo I 72 se han planteado diversas cuestiones en relación a la indeterminación del concepto de desamparo ${ }^{29}$, la atribución de la competencia para su declaración por parte de la Administración, y la relevancia que en estos procesos tiene el transcurso del tiempo ${ }^{30}$.

En efecto, con la aprobación de la Ley 26/20I 5, de 28 de julio, de modificación del Sistema de Protección a la Infancia y la Adolescencia, el legislador, haciéndose eco de las dificultades en torno a la regulación de las situaciones de desamparo y su declaración, divide el artículo I72 del CC en tres: el I72 referido a las situaciones de desamparo, el artículo I 72 bis, que contempla la guarda voluntaria a solicitud de los padres o tutores, y el 172 ter, que regula el acogimiento residencial o el familiar al que se somete al menor en cualquiera de los casos; y ello unido a la nueva redacción que la citada ley da los artículos I 8, I9 y 20 de la LOPJM, donde se regulan, respectivamente, las actuaciones en situación de desamparo, la guarda voluntaria de menores y el acogimiento familiar.

29. De Palma (20II) p. 20I: "teniendo en cuenta que la definición de desamparo que nos brinda el artículo I72 del CC adolece de imprecisión, todas las leyes autonómicas dictadas en materia de protección de menores han precisado supuestos concretos que darían lugar a una declaración de desamparo por la Administración; la existencia de malos tratos físicos o psíquicos; los abusos sexuales; la inducción a la mendicidad; la delincuencia o prostitución; los trastornos graves de los padres que impidan el cumplimiento de sus deberes de protección u otras situaciones similares. En todo caso, las diversas situaciones tiene un denominador común: las condiciones que padece el menor impiden o dificultan gravemente su desarrollo físico, psíquico o social $y$, en definitiva, el pleno desarrollo de su personalidad, por lo que resulta necesario adoptar medidas de protección que implican la separación de sus padres o tutores»; MORENO (2000) pp. I 558 -I 559.

30. BenAVEnte (20II) p. 2I: «resulta relevante, cara a su necesaria diferenciación con las situaciones de riesgo, varias cuestiones en relación con la declaración del desamparo de un menor: Por un lado, la indeterminación del concepto de desamparo; por otro, la atribución de la competencia para su declaración a la Administración (que no tendría tanta relevancia si no recayese precisamente sobre un concepto tan indeterminado) y, por otro, [...], la relevancia que en estos procesos tiene el transcurso del tiempo y la duración de los mismos, lo que evidentemente se pone de manifiesto en la mayoría de la decisiones que (...), han tenido un cierto eco social», en «Riesgo, desamparo y acogimiento de menores, actuación de la Administración e intereses en juego». 
La nueva redacción del artículo I 8 de la LOPJM completa la definición de la situación de desamparo regulada en el artículo I 72 del CC, estableciéndose, por primera vez en una norma de carácter estatal, tal y como se afirma en la Exposición de Motivos de la Ley 26/20 I 5 , de 28 de julio, las circunstancias que la determinan y una importante clarificación y unificación de criterios para su declaración; circunstancias que tanto la legislación autonómica, al amparo del artículo I49.I.8 CE y dentro del marco competencial atribuido a sus respectivos Estatutos de Autonomía ${ }^{31}$, como la jurisprudencia ya venían realizando ${ }^{32}$.

A pesar de la modificación del artículo I72 del CC la definición de desamparo sigue siendo la misma que la establecida por el legislador de I996, se considera como situación de desamparo la que se produce de hecho a causa del incumplimiento o del imposible o inadecuado ejercicio de los deberes de protección establecidos por las leyes para la guarda de menores, cuando éstos queden privados de la necesaria asistencia moral o material ${ }^{33}$. Si bien, la indeterminación del concepto o definición de la misma se concreta con la nueva redacción del artículo i 8 de la LOPJM, que establece una relación de circunstancias en virtud de las cuales podríamos entender que un menor se encuentra en situación de desamparo. Ahora bien, tal y como señala el legislador, estas situaciones tienen que ser de suficiente gravedad- que supongan una amenaza para la integridad física o mental del menor- valoradas y ponderadas conforme

3I. Todas las legislaciones autonómicas aprobadas con posterioridad a la LO I/I996, de I 5 de enero, de Protección Jurídica Menor y de modificación parcial del CC y de la LEC, recogen las situaciones de "riesgo» y "desamparo», desarrollando en cuál o cuáles circunstancias se puede entender que se da una u otra situación.

32. La jurisprudencia ha sido unánime respecto a los requisitos que ha de darse para la declaración de desamparo: I) Incumplimiento de los deberes, no sólo apreciables en los casos de abandono absoluto del menor, carente de personas que se hagan cargo de su guarda, sino que comprende también aquéllos supuestos en los que los guardadores incumplen de hecho, ejercen inadecuadamente o están imposibilitados para llevar a cabo aquellos deberes; 2) Privación de asistencia moral o material del menor. No obstante, para apreciar la situación de desamparo se han de examinar minuciosamente las circunstancias específicas de cada caso concreto, atendiendo fundamentalmente al interés del menor. DE PALMA (20II) p. 200. Sentencia 3 Io/2007 de I4 de junio AP de Cádiz, Auto 49/2008 de I I de junio AP Almería, Sentencia 2 I/2000 de I 5 de febrero AP Cádiz, Sentencia I65/2009 de 3 de julio AP Cuenca.

33. Sainz-Cantero (20I4) p. I23. STS de 27 de octubre de 2014 (recurso núm 2762/2013) y SSTC I43/I990 y 298/I993. 
a los principios de necesidad y proporcionalidad, para que dicha declaración pueda ser adoptada, pues conlleva la asunción de la tutela del menor por la Entidad Pública y la suspensión de la patria potestad o la tutela ordinaria ${ }^{34}$.

Sin ser exhaustivos en su desarrollo, las circunstancias o situaciones que recoge la nueva redacción del artículo I 8.2 de la LOPJM serían las siguientes: a) El abandono del menor; b) El transcurso del plazo de la guarda voluntaria; c) El riesgo para la vida, salud e integridad física del menor; d) El riesgo para la salud mental del menor, su integridad moral y el desarrollo de su personalidad debido al maltrato psicológico continuado o a la falta de atención grave y crónica de sus necesidades afectivas o educativas por parte de los progenitores, tutores o guardadores; e) El incumplimiento o el imposible o inadecuado ejercicio de los deberes de guarda como consecuencia del grave deterioro del entorno o de las condiciones de vida familiares; f) La inducción a la mendicidad, delincuencia o prostitución, o cualquier otra explotación del menor de similar gravedad; g) La ausencia de escolarización o falta de asistencia reiterada y no justificada adecuadamente al centro; h) Cualquier otra situación gravemente perjudicial para el menor que traiga causa del incumplimiento o inadecuado ejercicio de la patria potestad, la tutela o la guarda, cuyas consecuencias no puedan ser evitadas mientras permanezcan en su entorno de convivencia.

Nótese que, la situación de pobreza de los progenitores, tutores o guar-

34. Sobre este tema es de sumo interés el Asunto R.M.S. España (Demanda n. ${ }^{\circ}$ 28775/I2), Sentencia de Estrasburgo I 8 de junio de 20I3, donde el citado Tribunal Condena al Estado español por violación del artículo 8 del Convenio para la protección de los Derechos Humanos y de las libertades fundamentales (CEDH), entre los argumentos esgrimidos por el Tribunal para una correcta valoración del caso podemos señalar los siguientes: recuerda que, para un progenitor y su hijo estar juntos representa un elemento fundamental de la vida familiar, que el artículo 8 del CEDH tiene esencialmente por objeto, precaver al individuo de las injerencias arbitrarias de las Autoridades Públicas, que la desintegración de una familia constituye una medida muy grave que debe reposar en consideraciones inspiradas en el interés del niño y tener bastante peso y solidez; que la decisión de hacerse cargo la Administración de un niño, debe ser considerada como una medida provisional, que se suspenderá en cuanto las circunstancias lo aconsejen; que la ruptura del contacto con un niño muy joven puede conducir a una alteración creciente de su relación con su progenitor; que las autoridades nacionales tiene que adoptar todas las medidas necesarias para que los menores puedan llevar una vida familiar normal en seno de su propia familia antes de entregarla a una familia de acogida y posterior adopción. 
dadores no podrá ser tenida en cuenta para la valoración de la situación de desamparo. Sin embargo, tal y como ya hemos manifestado, sí se considera un indicador de desamparo, entre otros, el tener un hermano declarado en tal situación, salvo que las circunstancias familiares hayan cambiado de forma evidente.

\section{Autoridad competente para declarar la situación de desamparo}

La competencia para constatar si un menor se encuentra en situación de desamparo la tiene atribuida la Entidad Pública a la que en el respectivo territorio español se haya encomendado la protección de los menores (art. I72. I CC) $)^{35}$. En este sentido, los legisladores autonómicos han atribuido, a través del procedimiento legalmente establecido, a la respectiva Administración autonómica la competencia para constatar la situación de desamparo de los menores, y asumir la tutela automática con la consiguiente suspensión de la patria potestad o la tutela ordinaria ${ }^{36}$.

Así, cuando la Entidad Pública constate que un menor se encuentra en situación de desamparo deberá adoptar las medidas necesarias para su guarda, poniéndolo en conocimiento del Ministerio Fiscal y, en su caso, del juez que acordó la tutela ordinaria.

La tutela ex lege o administrativa se califica de automática porque se atribuye a la Administración pública por disposición legal, es decir, sin necesidad de intervención judicial previa. Sin perjuicio de que la autoridad judicial atribuya la guarda administrativa de un menor cuando constate que un menor se encuentra en situación de desamparo (art. I 72 bis, 2 CC).

La nueva redacción del artículo I 72 del CC en relación a la notificación de la resolución administrativa que declara la situación de desamparo establece que las medidas adoptadas se notificarán a los progenitores, tutores o guardadores y al menor si tuviere suficiente madurez y, en todo caso, si fuere mayor de 12 años. Especificando que la información deberá ser clara, comprensible y en formato accesible, incluyendo las causas que dieron lugar a la intervención

35. Según la Disposición adicional primera de la Ley 26/2015, de 28 de julio, de modificación del Sistema de Protección a la Infancia y a la Adolescencia «se utilizará en los textos legales «Entidad Pública» referida a la Entidad Pública de protección de menores competente territorialmente.

36. Moreno (2000) p. I 560. 
de la Administración y los efectos de la decisión adoptada. Además, la información, siempre que sea posible, se facilitará de forma presencial y, especialmente, en el caso de los menores será adaptada a sus condiciones de madurez. Por último, la resolución se notificará de forma inmediata sin que sobre pase el plazo máximo de 48 horas.

\section{Procedimiento para la declaración de desamparo}

Cuando la Administración, tras las comprobaciones iniciales, considere que un menor pudiera encontrarse en situación de desamparo deberá incoar y tramitar el oportuno procedimiento administrativo, para conocer la efectiva situación del menor. Procedimiento que podrá finalizar con la declaración de desamparo y la consiguiente asunción de la tutela del menor. No obstante, cuando la urgencia del caso así lo requiera, la Ley habilita a la Administración para adoptar la guarda provisional como medidas cautelar que le permita una atención inmediata del menor, incluso antes de iniciarse el procedimiento, y todo ello con base en el artículo I72. 4 del CC.

También, el artículo I4 de la LOPJM señala que:

La Entidad Pública podrá asumir, en cumplimiento de la obligación de prestar la atención inmediata, la guarda provisional de un menor prevista en el art. I72.4 del CC, que será comunicada al Ministerio Fiscal, procediendo simultáneamente a practicar las diligencias precisas para identificar al menor, investigar sus circunstancias y constatar, en su caso, la situación real de desamparo ${ }^{37}$.

Los procedimientos administrativos pueden iniciase de dos formas: de oficio por la propia Administración o a solicitud de persona interesada ( $c f r$. art. 68 LRJ-PAC). La mayoría de leyes autonómicas de protección de menores contemplan la iniciación del procedimiento únicamente de oficio por la Administración, configurando el procedimiento desde la perspectiva de producir efectos desfavorables. No obstante, parte de la doctrina considera que la legislación debería contemplar la posibilidad de que el procedimiento también se iniciara por solicitud de los interesados y, en concreto, a instancia del propio

37. Previsión legal conforme al art. 72.2 de la LRJ-PAC para la adopción de medidas cautelares. 
menor: en especial, en el caso de los adolescentes. (cfr. art. 35 de la $\mathrm{LO}_{4} / 2000$, de I I de enero, sobre derechos y libertades de los extranjeros en España y su integración social, en la redacción de la $\mathrm{LO}$ 2/2009, de I I de diciembre; y, el art. IO. 2 a) en relación con los apdos 3 y 4 tras la nueva redacción $)^{38}$.

El inicio del procedimiento administrativo de desamparo deberá ser notificado a todos los interesados y cuando las circunstancias lo aconsejen al propio menor. La notificación, siempre que sea posible, y especialmente en el caso del menor, se facilitará de forma presencial ${ }^{39}$.

Los interesados podrán presentar alegaciones y aportar documentos u otros elementos de juicio que estimen convenientes en cualquier momento del procedimiento anterior al trámite de audiencia. Asimismo, se les reconoce el derecho a conocer, en cualquier momento, el estado de la tramitación de los procedimientos administrativos y obtener copias de documentos contenidos en ellos. (cfr. arts. 35 a) y e), y el art. 79 de la LRJ-PAC) ${ }^{40}$. El órgano instructor del procedimiento podrá acordar la apertura de un periodo de prueba, por un plazo no superior a treinta días ni inferior a diez, a fin de que puedan practicarse cuantas se estimen pertinentes. Asimismo, también podrán solicitar la práctica de pruebas todos los interesados. Pruebas que sólo podrán ser rechazadas mediante resolución motivada. (art. 80 LRJ-PAC). Si bien, la Administración, en el caso de que concurra alguna circunstancia que aconseje una intervención urgente, podría declarar como medida cautelar en el curso del procedimiento y antes de su finalización, la situación de desamparo provisional, justificando dicha intervención.

Antes de redactar la propuesta de resolución tendrá lugar el trámite de audiencia, poniéndose a disposición de los interesados el expediente, para que puedan presentar alegaciones en un plazo no inferior a diez días ni superior

38. De Palma (20I I) p. 204.

39. En Cataluña, la Ley I 4/20ıo, de 27 de mayo, de los derechos y las oportunidades en la infancia y la adolescencia, prevé la notificación del acuerdo de incoación a los adolescentes (art. I06.2).

40. El TEDH ha declarado que el artículo 8 del CEDH requiere que el proceso decisorio que conduce a la adopción de medidas que supone una injerencia en la vida familiar sea equitativo y respete los intereses protegidos. Por ello, concluye que la falta de una posibilidad real, justa y suficiente de participar en el procedimiento de desamparo o en el adopción de las consiguientes medidas de protección constituye una violación del derecho a la vida familiar (STEDH de ıo de mayo 200 I, asunto T.P y K.M contra Reino Unido). 
a quince. En este trámite de audiencia los menores deberán ser escuchados de forma adecuada a su edad y grado de madurez ${ }^{41}$. (cfr. art. 9 LOPJM). Finalizado el trámite de audiencia y vista del expediente, el órgano instructor elaborará la propuesta de resolución sobre la procedencia o no de declarar el desamparo y, en su caso, las medidas de protección oportunas. Dicha propuesta de resolución junto con los documentos que forman el expediente administrativo, se trasladará al órgano administrativo competente para dictar la resolución.

La Administración deberá tramitar el procedimiento de desamparo y notificar la resolución final en un plazo que no podrá exceder de seis meses, a no ser que una norma con rango de ley disponga uno mayor. La resolución que ponga fin al procedimiento deberá estar debidamente motivada y deberá expresar la procedencia o no de la declaración de desamparo del menor y, en su caso, la propia resolución podrá contemplar las medidas de protección, el plan de reintegración familiar y el régimen de las medidas de protección. (cfr. arts. 42.2 y 3 y 54 LRJ-PAC).

Una vez dictada la resolución administrativa que declara la situación de desamparo y las medidas adoptadas, la nueva redacción del artículo I 72 del CC señala que:

se notificará en legal forma a los progenitores, tutores o guardadores y al menor afectado si tuviere suficiente madurez y, en todo caso, si fuese mayor de doce años, de forma inmediata sin que sobrepase el plazo máximo de cuarenta y ocho horas. La información será clara, comprensible, y en formato accesible, incluyendo las causas que dieron lugar a la intervención de la Administración y los efectos de la decisión adoptada, y en el caso del menor, adaptada a su grado de madurez. Siempre que sea posible y, especialmente, en el caso del menor, esta información se facilitará de forma presencial.

Por último, la resolución administrativa de desamparo deberá ser comunicada al Ministerio Fiscal, tal y como establece el artículo I72.I. del CC, y a la autoridad consular del Estado del que sean nacionales, en el que caso de que sean menores extranjeros no acompañados. Ahora bien, no se trata de una mera comunicación formal, sino que la comunicación de la resolución

4I. Los menores inmigrantes no acompañados podrán participar en este trámite asistido de asesor, cuando se considere conveniente para la defensa de los intereses (art. 85.2 LRJ-PAC). 
debe de ir acompañada de una copia del expediente administrativo, tramitado con el fin de permitir al Fiscal realizar un control de los aspectos formales y materiales de la actuación administrativa, dado que el artículo I72. 2 del CC legitima al Ministerio Fiscal para oponerse a las resoluciones administrativas dictadas en materia de protección de menores y, en su caso, promover ante la autoridad judicial otras actuaciones. En efecto, la nueva redacción del citado artículo establece que:

Durante el plazo de dos años desde la notificación de la resolución administrativa por la que se declare la situación de desamparo, los progenitores que continúen ostentando la patria potestad pero la tengan suspendida conforme a lo previsto en el apartado I, o los tutores que, conforme al mismo apartado, tengan suspendida la tutela, podrán solicitar a la Entidad Pública que cese la suspensión y quede revocada la declaración de situación de desamparo del menor, si por cambio de las circunstancias que la motivaron, entienden que se encuentran en condiciones de asumir nuevamente la patria potestad o la tutela.

Igualmente durante el mismo plazo podrá oponerse a las decisiones que se adopten respecto a la protección del menor.

Pasado dicho plazo decaerá el derecho de los progenitores o tutores a solicitar u oponerse a las decisiones o medidas que se adopten para la protección del menor. No obstante, podrán facilitar información a la Entidad Pública y al Ministerio Fiscal sobre cualquier cambio de las circunstancias que dieron lugar a la declaración de situación de desamparo.

En todo caso, transcurridos los dos años, únicamente el Ministerio Fiscal estará legitimado para oponerse a la resolución de la Entidad Pública...

Para finalizar, decir que la Ley 26/20I 5, de 28 de julio, de modificación del Sistema de Protección a la Infancia y la Adolescencia, para reforzar la tutela judicial efectiva en defensa de los intereses de los menores modifica varios preceptos de la LEC en relación al recurso de oposición respecto de todas las resoluciones administrativas en materia de protección de menores, unificando el plazo a dos meses para formular oposición, eliminando la diferenciación que hacía respecto de la declaración de desamparo. (Cfr.art. 780 . I. LEC) ${ }^{42}$. Y, el artículo 525.I de la LEC incluye de forma expresa, clara y terminante, la

42. EGEA (I995) p. 253-288. 
prohibición de ejecución provisional de las sentencias que se dicten en los procesos de oposición a las resoluciones administrativas en materia de protección de menores, con el fin de evitar perjuicios que para el menor de edad supondría la revocación de una sentencia de esta naturaleza que se estuviese ejecutando provisionalmente ${ }^{43}$.

3. Efectos de la resolución que declara la situación de desamparo: la tutela administrativa de los menores desamparados y la suspensión de la patria potestad

La resolución administrativa mediante la que se declara el desamparo de un menor tiene la peculiaridad de producir un doble efecto: de un lado, la atribución ope legis a la Administración de la tutela del menor; por otro, la suspensión de la patria potestad. A partir de ese momento, la Administración deviene responsable de la guarda del menor y es titular de los deberes y facultades inherentes a la misma. No obstante, serán válidos los actos de contenido patrimonial que realicen los progenitores o tutores en representación del menor y que sean en interés de éste (art. I72. I parrf. $3 .{ }^{a}$ del CC).

Dicha tutela administrativa se caracteriza por ser de titularidad pública, correspondiendo a las Entidades Públicas aunque delegable, como veremos con posterioridad a través del acogimiento familiar. A tal efecto, cada Entidad Pública designará al órgano que ejercerá la tutela de acuerdo con sus estructuras orgánicas de funcionamiento (art. I8.3 de la LOPJ) ${ }^{44}$.

En todo caso, si procediere, la Entidad Pública y el Ministerio Fiscal podrán promover la privación de la patria potestad y la remoción de la tutela. (art. I72.I. ${ }^{\circ}$, párrf. $4 .^{\circ}$ del CC). Posibilidad que se concede a la Entidad Pública tras la Ley 26/20I 5 , de 28 de julio, de modificación del sistema de Protección a la Infancia y a la Adolescencia.

Si bien, aunque la separación de la familia suele ser el efecto inmediato de declaración de desamparo, contrariamente a lo que ocurre con los menores en situación de riesgo, la situación legal de desamparo tiene como fin inmediato la búsqueda de la reinserción social del menor en su propia familia, o su inserción en otro ámbito familiar mediante la figura del acogimiento, lo que obliga a la Entidad Pública a buscar medidas de apoyo a la familia a través la elabo-

43. BOtANA (20I 5 ) p. I9-20.

44. De Pablo (I999) p. 54-55. 
ración de un plan individualizado de protección que establecerá los objetivos, la previsión y el plazo de las medidas de intervención a adoptar con su familia de origen, incluido, en su caso, el programa de reintegración familiar (art. I9 bis LOPJM y I 72 ter. 2 CC).

En este sentido, todas las medidas protectoras que adopte la Administración deberán ir encaminadas a la reintegración del menor en su propia familia de origen o, cuando las circunstancias lo aconsejen y valorando el interés superior del menor, a su incorporación en otra; respetándose así el derecho a la vida familiar proclamado en el artículo 8 del Convenio Europeo de Derechos Humanos, así como el principio de prioridad de la familia natural proclamado en la Declaración de la Asamblea General de las Naciones Unidas de 30 de diciembre de 1986 en su artículo 9 y que ahora se recoge en el artículo I I. 2, b) de la LOPJM como principio rector de la acción administrativa:

El mantenimiento en su familia de origen, salvo que sea conveniente para su interés, en cuyo caso se garantizará la adopción de medidas de protección familiares y estables priorizando, en estos supuestos, el acogimiento familiar frente al institucional.

Sin embargo, para la reintegración del menor en su familia de origen no basta con una evolución positiva de los padres biológicos, sino que es necesario que esta evolución sea suficiente para restablecer la unidad familiar en condiciones que supongan la eliminación del desamparo del menor. Para valorar esto último el legislador tiene en cuenta el tiempo transcurrido en la familia de acogida, que se hayan mantenido los vínculos, que concurra el propósito de desempeñar las responsabilidades parentales adecuadamente y que se constate que el retorno con ella no supone riesgos relevantes para el menor. En los casos de acogimiento familiar, deberá ponderarse el tiempo transcurrido y la integración en la familia de acogida y su entorno, así como el desarrollo de vínculos afectivos con la misma. Y, por último, en los casos de menores extranjeros no acompañados, se procurará la búsqueda de su familia y el restablecimiento familiar de la convivencia familiar, iniciando el procedimiento correspondiente, siempre que se estime que dicha medida responde a su interés superior y no coloque al menor o a su familia en una situación que ponga en riesgo su seguridad. (art. I9 bis. 3 y 5 , LOPJM) ${ }^{45}$.

45. GutiÉRrez (2004) p. I79. 
Ahora bien, atendiendo a la provisionalidad y temporalidad de las medidas, se establece como novedad que la Entidad Pública cesará en la tutela que ostente sobre los menores declarados en situación de desamparo cuando constate mediante los correspondientes informes la desaparición de las causas que motivaron su asunción, por alguno de los supuestos previstos en los artículos 276 y 277. I. del CC y cuando compruebe fehacientemente alguna de las siguientes circunstancias:

- Que el menor se ha trasladado voluntariamente a otro país.

- Que el menor se encuentra en el territorio de otra comunidad autónoma cuya Entidad Pública hubiere dictado resolución sobre declaración de situación de desamparo y asumido su tutela o medida de protección correspondiente, o entendiere que ya no es necesario adoptar medidas de protección a tenor de la situación del menor.

- Que haya transcurrido seis meses desde que el menor abandonó voluntariamente el centro de protección, encontrándose en paradero desconocido ${ }^{46}$.

Asimismo, la Entidad Pública, de oficio o a instancia del Ministerio Fiscal o de persona o entidad interesada, podrá revocar la declaración de situación de desamparo y decidir el retorno del menor con su familia, siempre que se entienda que es lo más adecuado para su interés (art. I72. 3. CC). El legislador no especifica, como sí se hacía en la regulación anterior, que tal decisión de revocar la situación de desamparo se puede hacer en todo momento, por lo que se entiende que puede ser así, esto es, en el plazo de dos años o transcurrido el mismo ${ }^{47}$.

46. Esta última causa de cesación de la tutela se ha introducido como novedad a petición de los directores de los centros de acogida de menores, al considerar que si los menores abandonaban voluntariamente el centro de acogida ellos no tenían por qué seguir teniendo la tutela del menor al no seguir aquéllos bajo su guarda y exonerarse de cualquier acto que pudiesen realizar los menores fuera del centro.

47. La anterior redacción del I 72 del Código civil establecía en el párrafo 7 que en el plazo de dos años desde la notificación de la declaración de la resolución administrativa por la que se declara el desamparo los padres que continúen ostentando la patria potestad podrán solicitar que cese la suspensión de la medida y que quede revocada la declaración de desamparo del menor, si por cambio de las circunstancias que lo motivaron, entienden que pueden asumir nuevamente la patria potestad. 


\section{Guarda provisional de menores solicitada por los progenitores o tutores y por resolución judicial}

La conocida guarda administrativa o voluntaria, solicitada por los progenitores o tutores ha sido regulada detenidamente tras la reforma de los artículos I9 de la LOPJM y I72 bis I. del CC, que le atribuyen una naturaleza esencialmente provisional.

Las Entidades Públicas, además de la tutela y correspondiente guarda de quienes han sido declarados en situación de desamparo, podrán asumir la guarda provisional de menores por solicitud de sus progenitores o tutores. Nótese que cuando éstos, por circunstancias graves y transitorias debidamente acreditadas, no puedan cuidar al menor, podrán solicitar de la Entidad Pública que ésta asuma su guarda durante el tiempo necesario, que no podrá sobrepasar dos años como plazo máximo, salvo que el interés del menor aconseje, excepcionalmente, la prórroga de la medida por la previsible reintegración familiar en un plazo breve de tiempo.

De esta forma, con la incorporación del plazo de dos años en la nueva redacción del precepto, se trata de evitar que se hagan crónicas las situaciones de guardas voluntarias en las que los progenitores ceden el cuidado de sus hijos a las administraciones públicas sine die, privándoles de soluciones familiares permanentes- acogimiento familiar- durante los años claves de la primera infancia ${ }^{48}$.

A su vez, con esta guarda administrativa o voluntaria se pretende evitar una futura declaración de desamparo cuando los progenitores o los tutores, siendo conscientes de las circunstancias en las que se encuentran, solicitan el auxilio de la Administración pública, así como castigar doblemente a las familias que social y económicamente se hallen en dificultad. Esta modalidad de guarda viene acompañada de un sistema de ayudas para paliar esta penosa situación ${ }^{49}$.

Ahora bien, las causas de imposibilidad material para el cuidado de los hijos deben estar suficientemente justificadas, con el fin de impedir que se utilice la guarda administrativa como medio caprichoso para eludir temporalmente los deberes que como progenitores o tutores les corresponde. Así, una vez que hayan desaparecido las causas, transcurrido el plazo de los dos años o la prórroga, el menor deberá regresar con sus progenitores o tutores o, si no se

48. BerRocal (2OI5) p. I 2.

49. Sainz-Cantero (20I4) p. I3 I. 
dan las circunstancias adecuadas para ello, será declarado en situación legal de desamparo.

Esta guarda administrativa o voluntaria se caracteriza por requerir solicitud frente a la tutela ex lege, que opera automáticamente por ministerio de la Ley. Por ello, la guarda administrativa o voluntaria se realizará por escrito dejando constancia de que los progenitores han sido informados de las responsabilidades que siguen manteniendo respecto del menor, así como de la forma en que dicha guarda va a ejercerse por la Entidad Pública, garantizándose, en el caso de los menores con discapacidad, la continuidad de los apoyos especializados que viniera recibiendo o la adopción de otros más adecuados a sus necesidades (art. I27 bis I apdo 2).

En estos supuestos de guarda voluntaria será necesario el compromiso de la familia de someterse, en su caso, a la intervención profesional, teniendo encuentra que el fin último de la guarda es la reintegración del menor en su entorno familiar. (art. I9.2 in fine LOPJM).

La resolución administrativa por la que se establece la asunción de la guarda por la Entidad Pública, así como sobre cualquier variación posterior de su forma de ejercicio, será fundamentada y comunicada a los progenitores o tutores y al Ministerio Fiscal.

Asimismo, la Entidad Pública asumirá la guarda administrativa por el plazo de dos años, o en su caso, la prórroga de tal plazo cuando así lo acuerde el juez en los casos en que legalmente proceda, adoptando para ello la medida de protección que resulte necesaria. (art. I9.I in fine LOPJM y I72 bis.2 CC).

Por tanto, la Entidad Pública, además de asumir la guarda de los menores en situación de desamparo, o en cumplimiento de la obligación de prestar la atención inmediata, la guarda provisional de un menor mediante resolución administrativa, podrá, igualmente, asumir la guarda provisional o temporal de un menor cuando sus progenitores o tutores no puedan cuidar de éste por circunstancias graves o transitorias, o cuando así lo acuerde el juez en los casos que legalmente proceda.

En todos y cada uno de las modalidades de guarda, la Entidad Pública elaborará un plan individualizado de protección que establecerá los objetivos, la previsión y el plazo de las medidas de intervención a adoptar con su familia de origen, incluido, en su caso, el programa de reintegración familiar. 


\section{El acogimiento: modalidades}

La regulación del acogimiento ha experimentado una sustancial reforma con la Ley 26/20I5, de 28 de julio ${ }^{50}$. En concreto, diversos artículos del Código civil relacionados con la materia han sido objeto de una nueva redacción- arts I 72 a I74- incluyendo la transformación del artículo I 72 en tres artículos I72, I 72 bis, I 72 ter, junto con un nuevo artículo I 76 bis, en sede de adopción, dedicado también a la guarda de menores ${ }^{51}$.

Como he tratado en apartados anteriores, desde que a la Entidad Pública se le atribuye, por ministerio de la Ley, la tutela y la correspondiente guarda de quienes están en situación de desamparo, hasta que el menor se reintegre en su propia familia o se dé en adopción, puede transcurrir un periodo de tiempo durante el cual al menor hay que buscarle un ámbito familiar o residencial idóneo. Teniendo como pauta general que el acogimiento residencial se constituye como una medida excepcional y provisional frente al acogimiento familiar (art 2I. I y 3 LOPJM).

\section{A. El acogimiento familiar}

Con la reforma se redefinen las medidas de acogimiento familiar en función de su duración y objetivos pasando a denominarse el acogimiento familiar simple a acogimiento familiar temporal ${ }^{52}$, se mantiene el acogimiento familiar permanente, y se introduce el acogimiento familiar de urgencia ${ }^{53}$. Quedando

50. Herrera (20I3) p. 87-89.

5I. Mendizabal (I997) pp. 247-258.

52. La redacción del artículo I73 bis del CC dada por la LO I/I996, definía el acogimiento familiar simple, como aquél que tenía carácter transitorio, bien porque de la situación del menor se prevea la reinserción de éste en su propia familia, bien tanto se adopte una medida de protección que revista un carácter estable.

53. En algunas Comunidades Autónomas como Andalucía ya se venían realizando el acogimiento familiar de urgencia. Esta modalidad de acogimiento es una medida que se aplica a menores sobre los que hay que intervenir de forma inmediata, evitando la institucionalización temprana y favoreciendo que gocen de un ambiente y atención familiar durante el tiempo necesario para realizar el estudio sobre la situación del/la menor y proponer bien la vuelta con su familia de origen, o la medida de protección más adecuada. Para llevar a cabo esta medida de protección las instituciones públicas cuentan con familias que de manera inmediata y con total disponibilidad pueden ha- 
suprimidos el acogimiento provisional ${ }^{54}$, así como el preadoptivo que se contempla como una fase del procedimiento de adopción (art. I76 y I76 bis del CC). Por tanto, tras la reforma, el acogimiento familiar podrá adoptar las siguientes modalidades:

- Acogimiento de urgencia: principalmente para menores de seis años, que tendrá una duración no superior a seis meses, mientras se decide la medida de protección familiar que corresponda.

- Acogimiento familiar temporal: que tendrá carácter transitorio, bien porque de la situación del menor se prevea la reintegración de éste en su propia familia, o bien en tanto se adopte una medida que revista un carácter más estable como el acogimiento familiar permanente o la adopción. Este acogimiento tendrá una duración máxima de dos años, salvo que el interés superior del menor aconseje la prórroga de la medida por la previsible e inmediata reintegración familiar, o la adopción de otra medida de protección definitiva. (arts I72. 4 CC y I4 LOPJM).

- Acogimiento familiar permanente: que se constituirá bien al finalizar el plazo de dos años de acogimiento temporal por no ser posible la reintegración familiar, o bien directamente en casos de menores con necesidades especiales o cuando las circunstancias del menor y su familia así lo aconsejen.

Hay dos tipos de acogimiento familiar en relación con las características de la familia acogedora y de la vinculación del menor con ésta. Así, el acogimiento podrá tener lugar en la propia familia extensa del menor o en familia ajena. Asimismo, el acogimiento en familia ajena podrá ser especializado, entendiendo por tal «el que se desarrolla en una familia en la que alguno de sus miembros dispone de cualificación, experiencia y formación específica para

cerse cargo del/la menor ante una situación de desprotección concreta. Esta medida de protección es de corta duración y suele aplicarse a menores de muy corta edad (de o a 6 años). El acogimiento familiar de urgencia tiene una duración mínima de 6 meses, prorrogables por otros 3 , y es remunerado en todos los casos.

54. El acogimiento familiar provisional fue una novedad introducida por la LO I/ı996 que se acordaba por la Entidad Pública cuando los padres no consentían o se oponían al acogimiento, subsistiendo hasta que se produjese resolución judicial, lo que obligaba a esperar a que se formalizase el acogimiento judicial, con la consiguiente lentitud y perjuicio psicológico para los niños privados innecesariamente de un ambiente familiar. 
desempeñar esta función respecto de menores con necesidades o circunstancias especiales con plena disponibilidad y percibiendo por ello la correspondiente compensación económica sin suponer en ningún caso una relación laboral». (art. 20.I apdo I LOPJM). El acogimiento especializado podrá ser a su vez profesionalizado cuando, reuniendo los requisitos anteriormente citados de cualificación, experiencia y formación específica, exista una relación laboral del acogedor o los acogedores con la Entidad Pública (arts. I73 bis. I del CC).

Como novedad, se simplifica la constitución del acogimiento familiar, equiparándolo al residencial, incluso aunque no exista previa conformidad de los progenitores o tutores, sin perjuicio del control jurisdiccional del mismo ${ }^{55}$. Y es que antes de la reforma, cuando los padres que no estuvieran privados de la patria potestad o el tutor fueran conocidos, eran necesarios sus consentimientos, pues en otro caso sólo podría ser acordado el acogimiento por el juez salvo que se tratase de un acogimiento provisional acordado por la Entidad Pública hasta que recayese resolución judicial de acogimiento ${ }^{56}$.

Por otra parte, y por razones de técnica jurídica y mejora de su ubicación, se traslada al artículo 20 de la LOPJM lo establecido hasta ahora en el artículo I73 del CC, sobre formalización del acogimiento y contenido del documento anexo que debe acompañar al mismo, y se introduce la necesidad, como ocurre en la adopción, de que se valore la adecuación de los acogedores definiéndose los criterios de la misma ${ }^{57}$.

El acogimiento familiar se formalizará por resolución de la Entidad Pública que tenga la tutela o la guarda, previa valoración de la adecuación de la familia para el acogimiento. En la valoración se tendrá en cuenta su situación familiar y la aptitud educadora, su capacidad para atender adecuadamente a las necesidades de toda índole del menor o menores de que se trate, la congruencia entre su motivación y la naturaleza y finalidad del acogimiento según su modalidad, así como la disposición a facilitar el cumplimiento de los objetivos del plan individual de atención a la familia de procedencia. El régimen de visitas podrá tener lugar en los puntos de encuentro familiar habilitados, cuando así lo aconseje el interés superior del menor con su familia de procedencia y aco-

55. SAinz-Cantero (2OI4) p. I42.

56. GisBert (I996) p. I 5 .

57. El Título III del Decreto 283/2002, de I 2 de noviembre, de acogimiento familiar y adopción en Andalucía, regula la metodología y los criterios generales para determinar la idoneidad de los acogedores y adoptantes. 
gedora. A su vez, cuando el tipo de acogimiento así lo aconseje, se valorará la adecuación de la edad de los acogedores con la del menor acogido, así como la relación previa entre ellos, priorizando, salvo que el interés del menor aconseje otra cosa, a las personas que perteneciendo a su familia extensa, reúnan las condiciones adecuadas para el acogimiento (art. 20.2 LOPJM $)^{58}$.

A la resolución de formalización del acogimiento familiar acordada, se acompañará un documento anexo, que incluirá los siguientes extremos:

- La identidad del acogedor o acogedores y del acogido.

- Los consentimientos y audiencias necesarias.

- La modalidad del acogimiento, duración prevista para el mismo, así como su carácter de acogimiento en familia extensa o en familia ajena, en razón de la vinculación del menor con la familia o persona acogedora; $y$,

- Los derechos y deberes de cada una de las partes, y en particular: I) El régimen de visitas, estancias, relación o comunicación, en los supuestos de declaración de desamparo, por parte de la familia de origen, que podrá modificarse por la Entidad Pública en atención al interés superior del menor; 2) El sistema de cobertura por parte de la Entidad Pública de los daños que sufra el menor o de los que pueda causar a terceros; 3 ) La asunción por parte de los acogedores de los gastos de manutención, educación y atención socio-sanitaria.

- El contenido del seguimiento que en función de la finalidad del acogimiento vaya a realizar la Entidad Pública y el compromiso de colaboración con dicho seguimiento por parte de la familia acogedora.

- En caso de menores con discapacidad, los recursos de apoyo que precisa;

- La compensación económica, apoyos técnicos y otro tipo de ayudas que, en su caso, vayan a recibir los acogedores; y,

- El plazo en el cual la medida vaya a ser revisada (art. 20.3 de la LOPJM).

Tanto la resolución de formalización del acogimiento como el documento anexo se remitirán al Ministerio Fiscal en el plazo de un mes.

El acogimiento familiar se podrá ejercer por personas casadas, solteras, pa-

58. MARTOS (2OII) p. 780. 
rejas de hecho e incluso miembros de un hogar funcional. En todo caso, no podrán ser acogedores los que no pueden ser tutores de acuerdo con lo previsto en la Ley. (art. I72. teri apdo. 2 del CC).

Si surgiera problemas graves de convivencia entre el menor y la persona o personas a las que hubiere sido confiada la guarda en acogimiento familiar, aquél, el acogedor, el Ministerio Fiscal, los progenitores o tutor que no estuvieran privados de la patria potestad o de la tutela o cualquier persona interesada podrá solicitar a la Entidad Pública la remoción de la guarda. (art. I73. $3 .^{\circ}$ del $\mathrm{CC})$.

Finalmente, el acogimiento familiar cesará: a) Por resolución judicial; b) Por resolución de la Entidad Pública, de oficio o a propuesta del Ministerio Fiscal, de los progenitores, tutores, acogedores o del propio menor si tuviera suficiente madurez, cuando se considere necesario para salvaguardar el interés del mismo; oídos los acogedores, el menor, sus progenitores o tutor; c) Por la muerte o declaración de fallecimiento del acogedor del menor; y, d) Por la mayoría de edad del menor ${ }^{59}$.

\section{A.1) Estatuto del acogedor familiar y de los menores.}

Por primera vez se regula el Estatuto del acogedor familiar y de los menores acogidos, como conjunto de derechos y obligaciones, ampliando así la seguridad jurídica y la cobertura legal necesaria, para que las familias acogedoras puedan desarrollar las funciones a las que están llamados, con plenas garantías de sus derechos para los menores acogidos. Y es que dada la transcendente función que desempeñan las familias de acogida se hacía muy conveniente, y así se había puesto de manifiesto desde diversos sectores, que una disposición general perfilase el estatus del acogedor familiar ${ }^{60}$.

Así, el artículo 20 bis de la LOPJM establece que los acogedores tendrán los siguientes derechos: Recibir información acerca de la naturaleza y efecto del acogimiento, así como una preparación previa, seguimiento y apoyo técnico especializado durante y el término del mismo. En caso de menores con discapacidad, los acogedores tendrán derecho a orientación, acompañamiento y apoyo adaptados a la discapacidad del menor; ser oído por la Entidad Pública antes de que ésta adopte cualquier resolución que afecte al menor, especial-

59. Gisbert (I996) p. I 5-I 8.

6o. Heras (2002) p. 236-258. 
mente antes de modificar o suspender temporalmente el régimen de una visita o de relación o comunicación con la familia de origen; ser informados del plan individual de protección así como de las medidas de protección relacionadas con el acogimiento que se adopten respecto al menor acogido, de las revisiones periódicas y a obtener información del expediente de protección del menor que les resulte necesaria para el ejercicio de sus funciones, a excepción de aquellas cuestiones que relacionadas con el derecho a la intimidad de terceros y a la protección de datos de carácter personal; ser parte en todos los procesos de oposición a las medidas de protección y a la declaración de desamparo del menor acogido y en todos los procesos de oposición relacionados con la medida de acogimiento familiar permanente con funciones de tutela que tenga formalizada; cooperar con la Entidad Pública en los planes de actuación y seguimiento establecidos para el acogimiento; disponer de la documentación identificativa, sanitaria y educativa del menor que acogen; ejercer todos los derechos inherentes a la guarda; ser respetado por el menor acogido; recabar el auxilio de la Entidad Pública en el ejercicio de sus funciones; realizar viajes con el menor siempre que se informe a la Entidad Pública y no exista oposición de ésta; percibir una compensación económica y otro tipo de ayuda que se hubiese estipulado, en su caso; facilitar al menor acogido las mismas condiciones que a los hijos biológicos o adoptados, a fin de hacer uso de sus derechos u obligaciones familiares durante el tiempo que convivan con ellos; relacionarse con el menor al cesar el acogimiento, si la Entidad Pública entiende que conviniere a su interés superior y lo consintiere la familia de origen o, en su caso, la familia adoptiva o de acogimiento permanente, y el menor si tuviere suficiente madurez y, en todo caso, si fuera mayor de doce años; ser protegidos sus datos personales respecto de la familia de origen, de acuerdo con la legislación vigente; formular formalmente quejas o sugerencias ante la Entidad Pública que deberán ser tramitadas en un plazo inferior a los 30 días y, en caso de solicitar audiencia, ser escuchado con anterioridad a dicho plazo; la familia acogedora tendrá los mismos derechos que, la Administración reconoce al resto de unidades familiares.

Por otra parte, y respecto del acogimiento familiar permanente, la nueva redacción del artículo $\mathrm{I} 73$ bis in fine establece que la Entidad Pública podrá solicitar del Juez que atribuya a los acogedores permanentes aquellas facultades de la tutela que faciliten el desempeño de sus responsabilidades, atendiendo, en todo caso, el interés superior del menor. Podríamos entender que con la incorporación de este texto el legislador ha querido solventar algunas de las 
lagunas que ni el legislador de I987 ni el I996 subsanaron en su momento, como a quién le correspondía el poder de decisión en aspectos fundamentales en la vida del menor acogido (elección de centro escolar, educación religiosa, tratamientos quirúrgicos) y a quién se le atribuía la representación del menor acogido, así como la administración de los bienes ${ }^{61}$.

$\mathrm{Y}$, conforme al artículo 20 bis 2 de la LOPJM tendrán los siguientes deberes: velar por el bienestar y el interés superior del menor, tenerlo en su compañía, alimentarlo, educarlo y procurarle una formación integral en su entorno afectivo.

En el caso de menor con discapacidad, deberá continuar prestando los apoyos especializados que viniere recibiendo o adoptar otros más adecuados a sus necesidades; oír al menor siempre antes de tomar decisiones que le afecten, si tuviere suficiente madurez y, en todo caso, si fuera mayor de I 2 años, sin exclusión alguna por discapacidad, y a transmitir a la Entidad Pública las peticiones que éste pueda realizar dentro de su madurez; asegurar la plena participación del menor en la vida de familiar; informar a la Entidad Pública de cualquier hecho de transcendencia en relación con el menor; respetar y facilitar las relaciones con la familia de origen del menor, en la medida de las posibilidades de los acogedores familiares en el marco del régimen de visitas establecido a favor de aquella y la reintegración familiar, en su caso; colaborar activamente con las Entidades Públicas en el desarrollo de la intervención individualizada con el menor y seguimiento de la medida, observando las indicaciones y orientación de la misma; respetar la confidencialidad de los datos relativos a los antecedentes personales y familiares del menor; comunicar a la Entidad Pública cualquier cambio en la situación familiar relativo a los datos y circunstancias que se tomaron en consideración como base para el acogimiento; garantizar el derecho a la intimidad y a la identidad de los menores acogidos y respeto a su propia imagen; así como velar por el cumplimiento de sus derechos fundamentales; participar en las acciones formativas que se propongan; colaborar en el tránsito de la medida de protección del menor a la reintegración a su entorno de origen, la adopción, u otra modalidad de acogimiento, o al entorno que se establezca tras la adopción de una medida de protección más estable; y, los acogedores familiares tendrán las mismas obligaciones respecto del menor acogido que aquellos que la ley establece para los titulares de la patria potestad.

En el artículo 2 I bis de la LOPJM se establecen los derechos de los meno-

6I. LiNANCERo (200I) p. 283-286; Diez (2004) p. 90-95. 
res acogidos, con independencia de la modalidad de acogimiento en que se encuentre, destacando entre otros: ser oído en los términos del artículo 9 y, en su caso, ser parte en el proceso de oposición a las medidas de protección y declaración en situación de desamparo de acuerdo con la normativa aplicable y en función de su edad y madurez. Para ello, tiene derecho a ser informado y notificado de todas las resoluciones administrativas de formalización y cese del acogimiento, ser reconocido beneficiario del derecho de asistencia jurídica gratuita cuando se encuentre en situación de desamparo; Dirigirse directamente a la Entidad Pública y ser informado de cualquier hecho trascendente relativo al acogimiento; relacionarse con su familia de origen en el marco de visitas, relación y comunicación establecida por la Entidad Pública; conocer progresivamente su realidad socio-familiar y sus circunstancias para facilitar la asunción de las mismas; recibir con la suficiente anticipación la información, los servicios y los apoyos generales que sean necesarios para hacer efectivos los derechos de los menores con discapacidad; poner en conocimiento del Ministerio Fiscal las reclamaciones o quejas que considere sobre las circunstancias del acogimiento; recibir el apoyo educativo y psicoterapéutico por parte de la Entidad Pública, para superar trastornos psicosociales de origen, medida esta aplicable tanto en acogimiento residencial como en acogimiento familiar; recibir el apoyo educativo y psicoterapéutico que sea necesario; y, acceder a su expediente y conocer los datos sobre sus orígenes y parientes biológicos, una vez alcanzada la mayoría de edad.

Además, en los supuestos de acogimiento familiar tienen los siguientes derechos: participar plenamente en la vida familiar del acogedor; mantener relación con la familia de acogida tras el cese del acogimiento si la Entidad Pública entiende que conviniere a su interés superior y siempre que lo consintiere el menor si tuviere suficiente madurez y, en todo caso, si fuera mayor de doce años, la familia de acogida, la de origen o, en su caso, la familia adoptiva o de acogimiento permanente; y solicitar información o pedir, por sí mismo, si tuviera suficiente madurez, el cese del acogimiento familiar.

Igualmente, en los supuestos de acogimiento residencial, tiene los siguientes derechos: respeto a la privacidad y a conservar sus pertenencias personales siempre que no sean inadecuadas para el contexto educativo; participar en la elaboración de programas de actividades del centro y en el desarrollo de las mismas, y, ser escuchado en caso de queja y ser informado de todos los sistemas de atención y reclamación a su alcancen incluido el derecho de audiencia en la Entidad Pública. 


\section{B. Acogimiento residencial}

Centrándonos ahora en el acogimiento residencial recordar que la Ley establece la prioridad del acogimiento familiar sobre el residencial. Así en el artículo I72 ter I. del CC se establece que:

se realizará mediante el acogimiento familiar y no siendo éste posible o conveniente para el interés del menor, mediante acogimiento residencial.

Y, según el artículo 2I. $3 .^{\circ}$ de la LOPJM:

Con el fin de favorecer que la vida de menor se desarrolle en un entorno familiar, prevalecerá la medida de acogimiento familiar sobre la del acogimiento residencial para cualquier menor, especialmente para menores de seis años. No se acordará el acogimiento residencial para menores de tres años salvo en supuestos de imposibilidad debidamente acreditada, de adoptar en ese momento la medida de acogimiento familiar o cuando esa medida no convenga al interés superior del menor. Esta limitación para acordar el acogimiento residencial se aplicará también a los menores de seis años en el plazo más breve posible. En todo caso, y con carácter general, el acogimiento de estos menores no tendrá una duración superior a tres meses.

El acogimiento residencial puede ser una medida de protección adecuada, una vez valoradas las circunstancias personales, familiares y sociales del menor. Esta modalidad de acogimiento implica que la Administración atribuya el ejercicio de los deberes de tutela o guarda del menor al director del centro procurando, de este modo, todas las atenciones necesarias para el correcto desarrollo y evolución del menor, bajo la vigilancia de la Entidad Pública, titular de tutela o guarda del menor y del Ministerio Fiscal ${ }^{62}$.

El objetivo del acogimiento residencial consiste en alojar a un menor en un centro adecuado a sus circunstancias donde pueda recibir la atención, educación y formación de la que carece en el seno familiar y que no exista otro recurso o cuando sea lo que más conviene al interés del menor cualquiera que sea su edad ${ }^{63}$.

62. GaYA (2015) p. 46-47.

63. Domínguez y Mohedano (2014) p.i52, «El acogimiento residencial puede 
A tal fin, se programan los recursos y medios necesarios para el retorno del menor a su familia o para la adopción de otras medidas. Para ello, se trabaja de forma individual con cada menor, atendiendo a las necesidades personales, familiares, escolares y sociales, planificando las actuaciones necesarias para el pleno desarrollo de su personalidad e integración social, sin dejar de promover alternativas, preferentemente de tipo familiar, ya sean con su familia extensa o ajena, pues los principios del sistema obligan a trabajar por la futura reintegración del menor con su familia propiciando el contacto exterior por lo que, en ocasiones, se ha utilizado como instrumento de transición entre el acogimiento familiar y la reintegración núcleo familiar biológico ${ }^{64}$.

Por otra parte, en lo relativo a los servicios de acogimiento residencial (denominados hasta ahora «servicios especializados» y ahora "acogimiento residencial» para utilizar una terminología equivalente al «acogimiento familiar»), se establece con carácter general sus características básicas y su necesario ajuste a criterios de calidad. Asimismo, todos los centros de acogimiento residencial que presten servicios dirigidos a menores en el ámbito de protección

ser un recurso adecuado; sin embargo, habrá que proveerlo de suficientes y variados recursos. Al igual que el acogimiento familiar que garantiza de partida el derecho del niño/niña a una familia en un contexto de apego más fácil. Bien realizado, el acogimiento residencial puede seguir teniendo su espacio según las necesidades y voluntad de niños/as y de sus padres/tutores», en "El acogimiento de menores en el actual sistema de protección a la infancia: la importancia del contexto».

64. A modo de ejemplo, el Auto 64/200I, de 8 de marzo, de la AP de Sevilla, señalo que: «Al acordarse de que se deje sin efecto el acogimiento, ha de decirse simultáneamente que la menor ha de volver con su madre, cuya recuperación de guarda y custodia ordenamos y, que por ello, y a fin de evitarle un daño derivado del tiempo que lleva conviviendo con los acogedores y separada de su madre, es procedente seguir un régimen transitorio consistente en transformar el acogimiento familiar en residencial provisional a fin de que al separarla de la familia acogedora e ir propiciando el acercamiento a su madre, no se le induzca a confusión entre ambas familias, duración residencial por el tiempo que aconsejen los informes y evaluaciones que deberán ir haciéndose respecto de la evolución de las visitas que la madre ha de hacerle en el centro; para acordar esto el tribunal ya cuenta con que este régimen transitorio lógicamente alguna perturbación temporal va a ocasionar en la menor, pero que queda supeditada al mayor beneficio que la recuperación de su madre se producirá en el futuro, de ahí que el tribunal no haya considerado necesario un informe pericial que valore la repercusión en la menor de tal medida». 
deberán estar siempre habilitados administrativamente por la Entidad Pública, debiendo respetar el régimen de habilitación dispuesto en la Ley 20/2013, de 9 de diciembre, de garantía de la unidad de mercado. Además, deberán existir estándares de calidad y accesibilidad por cada tipo de servicio.

Por su parte, la Entidad Pública regulará el régimen de funcionamiento de los centros de acogimiento residencial e inscribirá en el Registro correspondiente a las entidades de acuerdo con sus disposiciones, prestando especial atención a la seguridad, sanidad, accesibilidad para personas con discapacidad, ratio y cualificación profesional de su personal, proyecto educativo, participación de los menores en su funcionamiento interno y de más condiciones que contribuyan a asegurar sus derechos; y, promoverán modelos de acogimiento residencial con núcleos reducidos de menores que convivan en condiciones similares a las familiares.

El centro es también sede jurídica de cada menor acogido, por lo que en su organización y sistema se debe garantizar el efectivo ejercicio de los derechos y el cumplimiento efectivo de los derechos y deberes del menor, así como la actuación de todas las garantías jurídicas que derivan tanto del estatuto jurídico del menor, como de la relación jurídica de tutela o guarda que le une con la Entidad Pública. A este respecto, ésta deberá realizar la inspección y supervisión de los centros y servicios semestralmente y siempre que así lo exijan las circunstancias. Por su parte, el Ministerio Fiscal deberá ejercer la vigilancia sobre las decisiones de acogimiento residencial, analizando, entre otros, los proyectos educativos individualizados, el proyecto educativo del centro y el reglamento interno ${ }^{65}$.

Por último, señalar que los servicios y centros donde se encuentren los menores en acogimiento deberán actuar conforme a los principios rectores de la ley y con pleno respeto a los derechos de los menores acogidos, teniendo las

65. El Defensor del Pueblo en su informe sobre Centros de Protección de Menores con trastornos de conducta y en dificultad social, Madrid, 2009, destacó, como deficiencia grave, la falta de seguimiento frecuente de la situación del menor en los centros por parte de las Administraciones competentes, cuando son éstas las responsables de asegurar la protección de los derechos de los menores. Es este sentido, afirmó que la vigilancia de la situación de los menores en los centros, al menos semestralmente, que los fiscales deberían realizar por orden del I74 CC es muy escasa, aunque es más frecuente cuando, lamentablemente, se hace convivir a menores en régimen de protección junto con menores que cumplen medidas de justicia juvenil. 
siguientes obligaciones básicas: a) asegurarán la cobertura de las necesidades de la vida cotidiana y garantizarán los derechos de los menores adaptando su proyecto general a las características personales de cada menor, mediante un proyecto socio-educativo individual, que persiga el bienestar del menor, su desarrollo físico, psicológico, social y educativo en el marco del plan individualizado de protección que defina la Entidad Pública; b) contarán con el plan individual de protección de cada menor que establezca claramente la finalidad de ingreso, los objetivos a conseguir y el plazo para su consecución; c) adoptarán todas sus decisiones en relación con el acogimiento residencial de los menores en interés de los mismos; d) fomentarán la convivencia y la relación entre hermanos siempre que ello redunde en interés de los menores y procurarán la estabilidad residencial de los menores, así como que el acogimiento tenga lugar preferentemente en un centro ubicado en la provincia de origen del menor ${ }^{66}$; f) potenciará la educación integral e inclusiva de los menores, con especial consideración a las necesidades de los menores con discapacidad, y velarán por su preparación para la vida plena, de manera especial su escolarización y formación. En el caso de los menores de dieciséis a dieciocho años uno de los objetivos prioritarios será la preparación para la vida independiente, la orientación e inserción laboral; g) poseerán una normativa interna de funcionamiento y convivencia que responda a las necesidades educativas y de protección, y tendrán regulado un procedimiento de formulación de quejas y reclamaciones; h) administrarán los medicamentos que en su caso, precisen los menores bajo prescripción y seguimiento médico, de acuerdo con la

66.A tal efecto, también se modifica el artículo I6I del CC al preverse que en caso de menor acogido, la Entidad Pública que en el respectivo territorio esté encomendada la protección de menores regulará las visitas y comunicaciones que correspondan a los progenitores y asimismo, los abuelos, hermanos y demás parientes y allegados, pudiendo acordar, en su caso de forma motivada y en interés del menor, la suspensión temporal de las mismas previa audiencia de los afectados y del menor si tuviere suficiente madurez, y, en todo caso, si fuera mayor de doce años, con inmediata notificación al Ministerio Fiscal. Para ello, el Director del centro de acogimiento residencial o la familia acogedora u otros agentes o profesionales implicados informarán a la Entidad Pública de cualquier indicio de los efectos perjudiciales o nocivos que tales visitas, y comunicaciones puede tener sobre el menor. No obstante, el menor, los afectados y el Ministerio Fiscal podrán oponerse a tales resoluciones administrativas conforme a la LEC. 
praxis profesional sanitaria; i) revisarán periódicamente el plan individual de protección con el objeto de valorar la adecuación del recurso residencial a las circunstancias personales del menor; j) potenciará las salidas de los menores en fines de semana y periodos vacacionales con sus familias de origen o, cuando ello no fuese posible o procedente, con familias alternativas; $\mathrm{k}$ ) promoverán la integración normalizada de los menores en los servicios y actividades de ocio, culturales y educativas que transcurran en el entorno comunitario en el que se encuentran; 1) establecerán los necesarios mecanismos de coordinación con los servicios sociales especializados para el seguimiento y ajuste de las medidas de protección; $\mathrm{m}$ ) velarán por la preparación para la vida independiente, promoviendo la participación en las decisiones que le afecten, incluida la propia gestión del centro, la autonomía y la asunción progresiva de responsabilidades; $y, n)$ establecerán medidas educativas y de supervisión que garanticen la protección de los datos personales del menor al acceder a las tecnologías de la información y de la comunicación y a las redes sociales.

Para finalizar, resaltar la obligación de preparar para la vida independiente a los jóvenes ex tutelados, estableciéndose en el nuevo artículo 22 bis de la LOPJM que:

Las Entidades Públicas ofrecerán programas de preparación para la vida independiente dirigidos a los jóvenes que estén bajo una medida de protección, particularmente en acogimiento residencial o en situación de especial vulnerabilidad, desde dos años antes de su mayoría de edad, una vez cumplida esta, siempre que lo necesiten, con el compromiso de participación activa y aprovechamiento por parte de los mismos. Los programas deberán propiciar seguimientos socioeducativo, alojamiento, inserciónlaboral, apoyo psicológico y ayudad económicas.

\section{El Ministerio Fiscal como superior vigilante de la actuación administrativa en protección de menores}

Con la nueva redacción del artículo I74 del CC se vuelve a reforzar la intervención del Ministerio Fiscal en el ámbito de la protección de menores ${ }^{67}$. El citado precepto afirma que «incumbe al Fiscal la superior vigilancia de la tute-

67. MOReno (2000) p. I 589-I 592. 
la, acogimiento o guarda de menores a que se refiere esta sección; que «habrá de comprobar, al menos semestralmente, la situación del menor, y promoverá ante el juez las medidas de protección que estime necesarias». A tal efecto, la Entidad Pública deberá dar noticia inmediata al Fiscal no ya sólo de los nuevos ingresos, sino también «enviarle copia de las resoluciones administrativas, variación y cesación de tutelas, guardas y acogimientos. Igualmente le dará cuenta de cualquier novedad de interés en las circunstancias del menor.

En el mismo sentido y en relación a las altas funciones que se le encomiendan al Ministerio Fiscal se establece en la Exposición de Motivos de la Ley 26/20I 5, de 28 de julio, que éstas «deben verse acompañadas de los suficientes medios a fin de que puedan ejercerlas de manera efectiva, evitando que sus esfuerzos queden limitados a un simple voluntarismo carente de operatividad práctica o que su actuación sea meramente simbólica». Para ello, se le asigna, en el nuevo apartado 4, la posibilidad de solicitar informes adicionales a los presentados por la Entidad Pública:

Para el cumplimiento de la función de la superior vigilancia de la tutela, acogimiento o guarda de los menores, cuando sea necesario, podrá el Ministerio Fiscal recabar la información de informes por parte de los servicios correspondientes de las Administraciones Públicas competentes... ${ }^{68}$.

Podríamos decir que las funciones en el marco de las instituciones de protección de menores (tutela, guarda y acogimiento), serías las siguientes ${ }^{69}$ :

- Incumbe la superior vigilancia de la tutela guarda y acogimiento de menores en los términos del citado artículo I74 del CC. Para ello debe ponerse en conocimiento del Ministerio Fiscal: la declaración de desamparo y la constitución de la tutela ex lege (art. I72 .I CC), cualquier variación posterior de la forma de ejercicio o de la guarda asistencia será comunicada a los padres tutores y al Ministerio Fiscal (art. I72.2 CC), remisión del documento de formalización del acogimiento familiar al Ministerio Fiscal (art. I72. ter apdo 2 CC), recabar la elaboración de informes por parte de los servicios correspondientes de las Administraciones Públicas competentes; para la defensa y garantías de sus derechos puede el menor poner en conocimiento del Ministerio Fiscal las situa-

68. VALerRa (I997) p. $28 \mathrm{I}$.

69. Bercovitz (20I 5) p. 2; LiNACERo (200I) p. 34I-346 
ciones que considere que atentan contra sus derechos, con el fin que éste promueva las acciones oportunas (art. I0.2 apdo b, LOPJM).

- Y, en el ámbito jurisdiccional, el art. 4 de la Ley de Jurisdicción voluntaria señala que el Ministerio Fiscal «intervendrá en los expedientes de jurisdicción voluntaria cuando afecten al estado civil o condición de la persona o esté comprometido el interés de un menor o una persona...»; así como el art. 749 de la LEC, tras la nueva redacción dada por la Ley de Jurisdicción voluntaria, refuerza de nuevo la superior vigilancia del Ministerio Fiscal en los procesos sobre capacidad filiación, matrimonio y menores, regulados en el Libro IV, Título I ${ }^{70}$.

- Dado el objeto de este trabajo, especial mención merece, en relación con la medida de acogimiento residencial, la obligación por parte del Ministerio Fiscal de visitar con cierta regularidad los centros, ya sean de gestión pública o privada, con el fin de constatar el buen funcionamiento y organización de los mismos y dar curso a las sugerencias o quejas de los profesionales y menores que día a día conviven al amparo de nuestro sistema. Este deber de vigilancia se concreta sobre las decisiones de acogimiento residencial que se adopten, la inspección sobre todos los servicios y centros de acogimientos residencial, análisis de los proyectos educativos individualizados, el proyecto educativo del centro y reglamento interno, brindándoles la oportunidad a los menores de ser ellos mismos quienes informen directamente al Fiscal de su situación y de aquellas situaciones que consideren que afectan a sus derechos e intereses, con el fin de que promuevan las acciones oportunas.. Ello no obsta la obligación de la Entidad Pública competente en lo que se refiere a la inspección y supervisión de los centros y servicios siempre que las circunstancias así lo exijan y como mínimo semestralmente. (cfr. arts. IO. 2 b), y 2 I. 4 y 5 , LOPJM) $)^{71}$.

Y para terminar, señalar que se establece en el artículo 22 ter de la LOPJM la creación de un sistema de información estatal sobre protección de menores a realizar por las Entidades Públicas y la Administración general del Estado que permitirá el conocimiento uniforme de la situación de la protección a la infancia y a la adolescencia en España, no sólo a los efectos estadísticos, sino

70. MORAL (I998) p. I89-223.

7I. Sainz-Cantero y Pardo (2010) p. I9-24. 
también de seguimiento concreto de las medidas de protección adoptadas respecto de cada menor, así como de las personas que se ofrecen para el acogimiento o la adopción.

\section{Conclusiones}

A modo de conclusión considero de forma generalizada que la reforma llevada a cabo por el legislador español en el sistema de protección a la infancia y a la adolescencia es oportuna, necesaria y acertada que nos permite crear un maco legal común y la coordinación entre los diversos sistemas legislativos autonómicos y del resto de los sistemas públicos, teniendo en cuenta la abundante legislación en materia de protección de menores con la que cuenta el Ordenamiento Jurídico español.

Igualmente ha sido muy acertada la revisión de los principios rectores de la actuación administrativa dentro del sistema de protección a la infancia y la adolescencia, puesto que algunos de los principios precisaba una mejora en la redacción y concreción para una correcta aplicación de los mismos, tal es el caso del principio del interés del menor; así como la introducción de otros nuevos principios como consecuencia ya no sólo de los diferentes instrumentos internacionales que han sido ratificados por el Estado español, sino también por la concienciación social que se debe tener sobre la protección de los menores que casi se eleva a categoría de obligación, como es el caso del párrafo 2 del artículo i i de la LOPJM.

Nótese que el legislador quiere reforzar en el sistema normativo el carácter de las medidas de protección adoptadas en relación a los menores, primando las medidas familiares frente a las residenciales, las estables frente a las temporales y las consensuadas frente a las impuestas, así como el carácter progresivo y flexible de las medidas acordadas por parte de la Entidad Pública, sin olvidar que la actuación de la Administración es siempre subsidiaria respecto de los progenitores. En este sentido, es plausible la adopción de algunos plazos que establece el legislador en la adopción de algunas de las medidas, así como en la revisión de las mismas. Un claro ejemplo de ellos es el plazo de dos años para la guarda voluntaria del menor del artículo i9 de la LOPJM.

De suma importancia y más que necesaria ha sido la nueva redacción del artículo I7 de la LOPJM, dado que la definición y concreción de la situación de riesgo fue una de las claras deficiencias del legislador de I996, lo que provocó la ingente legislación autonómica con la que contamos hoy en el Ordenamien- 
to Jurídico español. Es por ello que, con la nueva redacción el legislador ha dado un completo desarrollo a la situación de riesgo, determinando la competencia para apreciarla y estableciendo el procedimiento para declararla.

En cuanto a la situación de desamparo, se aborda de una manera más rigurosa en los artículos I 8 de la LOPJM y en el artículo I 72 del CC, estableciéndose, y aquí su importancia, una norma con carácter estatal que era más que necesaria, realizando el legislador una clarificación y unificación de criterios para su declaración.

Igualmente de relevantes son las nuevas modalidades acogimiento. El legislador ha unificado algunas y suprimidas otras, haciéndose eco de la dificultad que entrañaban, y las críticas ya no sólo por parte de la doctrina civilista sino también de las entidades públicas responsables de los procedimientos de acogimiento y, en concreto, en relación al acogimiento preadoptivo.

Y, finalmente se hace patente, el refuerzo que la nueva legislación otorga al Ministerio Fiscal en todo lo concerniente a las acciones en materia de protección de menores, sobre todo en el seguimiento que tiene hacer dicha institución de las medidas acordadas en torno a estos. No sólo se trata de acordar medidas de protección sino que todas las medidas persigan una finalidad, siendo la primordial el regreso del menor con su familia de origen y, en su caso, la adaptación del menor y su inclusión social y laboral una vez que el menor haya cumplido la mayoría de edad, a través de programas para la preparación de vida independiente.

\section{Referencias}

Allueva, L. (20II): "Situaciones de riesgo y desamparo en la protección de menores». En Revista InDret, 20I I, pp. 2-25.

Herrera, Ramón (coord.) (2000): "Homenaje al Profesor Bernardo Moreno Quesada». (Ediciones Universidad de Almería, Vol. III).

Rams, Joaquín (2000): «Comentarios al Código Civil» (Editorial J. M. Bosch, Vol. I-III).

SÁnchez, Francisco (coord.) (2013): «Curso de de Derecho Civil I bis, Derecho de Familia». (Valencia, Tirant lo Blanch, $2^{\text {a }}$ edición).

Moreno, Oscar (coord.) (2006): "Código civil y jurisprudencia concordada». (Madrid, Imprenta Nacional del Boletín Oficial del Estado).

Ruíz-Rico, José (2009): "Código de leyes civiles». (España, Tecnos).

BAEZA, Gloria (200I): "El interés superior del niño: derecho de rango consti- 
tucional. Su recepción en la legislación nacional y aplicación en la Jurisprudencia». En Revista Chilena de Derecho, Pontificia Universidad Católica de Chile, Vol. 28, n ${ }^{\circ}$ 2, abril-junio 20I I, p. 355-362.

Benavente, Pilar (20I I): «Riesgo, desamparo y acogimiento de menores, Actuación de la Administración e intereses en juego». En AFDUAM, Universidad Autónoma de Madrid, no I 5, 20I I, p. I 5-62.

Bercovitz, Rodrigo (I999): «¿Protección de menores versus protección de progenitores?». En Actualidad civil, I999-III, p. 2195.

Bercovitz, Rodrigo (201 5): «La guarda y acogimiento de menores». En Revista Doctrinal Aranzadi civil-mercantil, Aranzadi, nº 9, 201 5, pp. I-4.

Berrocal, A. (20I 5): "Las instituciones de protección a la infancia y adolescencia: atención inmediata, situación de riesgo y desamparo, tutela administrativa y acogimiento familiar y residencial tras la Ley 26/20I 5 ». En La Ley, Derecho de familia, 201 5, p. I-25.

Botana, G. (201 5): "La Ley 26/20I 5, de 28 de julio, de modificación del sistema de protección a la infancia y a la adolescencia». En Actualidad Civil, Aranzadi, $\mathrm{n}^{\circ}$ 2, 20I 5, p. I- 20.

Campo, A. (2015): "Análisis de la Ley orgánica 8/2015, de 22 de julio, de modificación del sistema de protección a la infancia y a la adolescencia». En La Ley, Derecho de familia, 20 I 5, p. I-I I.

Cillero, Miguel (I 999): «El interés superior del niño en el marco de la Convención internacional sobre los Derechos del Niño». En Justicia y Derechos del Niño, UNICEF, ${ }^{\circ}$ I, I999, p 48-63.

De Palma, Ángeles (20I I): «El derecho de los menores a recibir protección: el papel de la familia y de las administraciones públicas. La actuación de las administraciones públicas en situación de riesgo, dificultad social y desamparo de los menores». En AFDUAM, Universidad Autónoma de Madrid, $\mathrm{n}^{\circ}$ I 5, 2OII, p. I85-2I 5 .

De La Rocha, Ernesto (2000): «Los menores de edad en el Derecho español» (Barcelona, Atelier).

De Pablo, P. (I999): "Situaciones de desamparo y situaciones de riesgo de desprotección social de los menores en la Ley Orgánica I/I996, del I 5 de enero, de Protección jurídica del Menor, en La desprotección social de los menores y las instituciones de amparo reguladas en la LOPJM», p. 49-62.

Diez, Helena (2004): «El acogimiento familiar simple como una de las formas de ejercer la guarda de menores» (Madrid: Ministerio de Trabajo y Asuntos Sociales). 
Diez, Helena (2003): «iEl imposible retorno del menor acogido a su familia de origen?». En Revista Derecho privado, Editorial Reus, año n ${ }^{\circ 7}$, mes 2, p. I66-208.

Domínguez, Javier y Mohedano, Roberto (2014): «El acogimiento de menores en el actual sistema de protección a la infancia: la importancia del contexto». En Revista Internacional de Trabajo social, Universidad de Murcia, ${ }^{\circ} 3$, p. I49-I 55 .

EGEA, JoAN (2OI 5): «La doctrina constitucional sobre la oposición judicial a la declaración de desamparo hecha por la entidad pública». En Derecho Privado y Constitución, Centro de Estudios Políticos y Constitucionales, $\mathrm{n}^{\circ}$ 5, I995, pp. 253-288.

Gaya, verónica (2015): "Menores en situación de desamparo». En Revista El Siglo, El Punto de Prensa S. A., $n^{\circ}$ I I I 8, junio 20I 5, pp. 46-47.

Gisbert, María Teresa (I996): «Ley de protección jurídica del menor». En Boletín oficial de información, Ministerio de Justicia, n ${ }^{\circ}$ 7776, p. 5-28.

Gómez, M. C. (2000): «El interés superior del niño», En Gaceta jurídica, n 328, p. 23-26.

GonzÁlez, Cristina (I996): «La aplicación en España del Convenio de la Haya de 29 de mayo de 1993, relativo a la protección del niño y a la cooperación en materia de adopción internacional». En Revista Jurídica de Cataluña, Academia de Jurisprudencia y Legislación de Cataluña y Colegio de Abogados de Barcelona, vol. 95, n² 2, p. 313-346.

Guilarte, Cristina (2OI4): "La concreción del interés del menor en la Jurisprudencia del Tribunal Supremo» (Valencia, Tirant Lo Branch).

GutiéRrez, P. (2004): «La problemática de reinserción en su familiar de origen del menor acogido». En Revista Derecho Privado y Constitución, p. I7I-34I.

Heras, María (2002): «El acogimiento convencional de menores» (Madrid, Montecorvo).

Herrera, R. (20I3): «Adopción, acogimiento y patria potestad, en Curso de de Derecho civil I Bis, Derecho de familia» (Coord. Sánchez), 2ª ed., p. 86-90.

Herrera, Ramón (2OI I): «Derecho y familia en el siglo XXI» (Almería, Universidad de Almería, Servicio de Publicaciones).

Iglesia, M. I. (20015): "Ley orgánica de modificación del sistema de protección a la infancia y a la adolescencia: las garantías de una protección uniforme a los menores más vulnerables en base a su supremo interés». En Diario La Ley, $\mathrm{n}^{\circ} 8.590$, pp. I-6. 
Linacero, María (200I): «Protección jurídica del menor» (Madrid, Montecorvo).

López, Rocío (200I): "La capacidad contractual del menor» (Madrid, Dykinson).

Martínez, C. (2007): "Los sistemas de protección de menores en la España de las autonomías», pp. 96-100.

Martos, María (20 I I): "Acogimiento familiar en la Comunidad andaluza: un reto en la protección de menores». En Derecho y familia en el siglo XXI», Vol. I, (Almería, Universidad de Almería), pp. 779-775.

Mendizabal, Luis (I997): "Derecho de menores» (Barcelona, Editorial Bosch).

Moral, Antonio (1998): "Menores y Ministerio Fiscal». En "El menor en la legislación actual», (Madrid, Fundación Antonio de Nebrija), pp. I89-I98.

Moreno, R. (2000): "Comentario a los artículos del Código Civil, artículos I72 a I74, sección I. ${ }^{\circ}$, De la Guarda y acogimiento de menores». En «Comentarios al Código Civil», (Coord. Rams Albesa), Vol. III, p. I 547- I 592.

Moreno-Torres, J. (2007): "La aplicación práctica del interés del menor en el sistema de protección de menores, Nudos Servicios Sociales». En Revista de los profesionales de los servicios sociales de la Provincia de Jaén, pp. 9-I4.

NúÑEZ, C. (I996): "Algunas consideraciones sobre la Ley orgánica I/I996, de I 5 de enero, de protección jurídica del menor», La Ley, pp. I-7

PÉrez, Miguel Ángel (I999): "La desprotección social del menor: una visión general en materia de instituciones de protección de menores». En "La desprotección social de los menores y las instituciones de amparo reguladas en la Ley Orgánica de protección jurídica del menor» (La Coruña, Servicio de Publicaciones, Universidade da Coruña), pp. 23-36.

Ravetllat, I. (20 5): "El interés superior del niño a la luz del nuevo art. 2 de la LO I/I996, de I 5 de enero». La Ley Derecho de Familia, 20 I 5, La Ley digital, pp. I-I4.

Rivero, Francisco (2000): «El interés del menor». En «Homenaje al Profesor Bernardo Moreno Quesada», Vol. III, (Almería, Universidad de Almería), pp. I $537^{-1} 567$.

RocA, Juan (2000): "Desamparo de menores: problemas de competencia y cuestiones procesales», En «Homenaje al Profesor Bernardo Moreno Quesada», Vol. III, (Almería, Universidad de Almería), pp. I 58 I-I 593.

SABATER, E. (I996): "La nueva ley de protección jurídica del menor», (Madrid, Actualidad Aranzadi), pp. I-4. 
SAINZ-Cantero, María (20I4): «El modelo común para la intervención con menores en riesgo y desamparo propuesto por el anteproyecto de ley de protección de la infancia». En Revista de Derecho Civil, Vol. I, n 4, pp. IO7-I 53.

SaInZ-Cantero, María y Pardo, E. (20I0): "Régimen Jurídico de los centros de protección y de reforma de menores».

SánCHEZ-CALERo, M. (20II): "El interés superior del menor y la interpretación restrictiva de las limitaciones a la capacidad de obrar de los menores en la ley orgánica I/I996, de I 5 de enero, de protección jurídica del menor». En «Derecho y familia en el siglo XXI», Vol. II, (Almería, Universidad de Almería), pp. 847-863.

Toldrá, María (2006): «La anulabilidad por causa de incapacidad (reflexiones en torno al artículo I 304 del Código civil)».

VAlera, C. (1997): "Comentario a la Ley orgánica I/I996, de I 5 de enero, de protección jurídica del menor: principios programáticos y normas de conflicto». En Actualidad civil, ${ }^{\circ}{ }^{\mathrm{I}} 2 / \mathrm{I} 7, \mathrm{pp} .26 \mathrm{I}-282$. 